\title{
La I Bienal Centroamericana de Pintura y la presencia de Marta Traba en la prensa costarricense y guatemalteca, I970-I979
}

\section{The First Central American Biennial of Painting and the Presence of Marta Traba in the Costa Rican and Guatemalan Press, 1970-1979}

Artículo recibido el 5 de agosto de 2020; devuelto para revisión el 16 de marzo de 202I; aceptado el 28 de abril de 202I; https://doi.org/IO.2220I/iie.I8703062e.202I.II9.2763

Sofía Vindas Solano Universidad de Costa Rica, Instituto de Investigaciones en Arte, sofia. vindas@ucr.ac.cr, http://orcid.org/oooo-0002-7618-282X

Líneas de investigación Caricatura; arte moderno; arte contemporáneo; arte centroamericano; patrimonio cultural; políticas culturales; curaduría y museos.

Lines of research Caricature; modern art; contemporary art; Central American art; cultural heritage; cultural policies; curatorship and museums.

Publicación más relevante "Cerdos que se alimentan con oro: el imperialismo yankee en las caricaturas costarricenses 1900-1930”, ISTMICA. Revista de La Facultad de Filosofía y Letras, núm. 2I (septiembre de 20I8), 95-I48. https://www. revistas.una.ac.cr/index.php/ istmica/article/view/I084I/13745

Resumen El artículo analiza las reacciones suscitadas por el fallo del jurado de la Primera Bienal Centroamericana de Pintura en 1971, tanto en la prensa costarricense como guatemalteca. En el primer apartado se contextualiza la postura de Marta Traba sobre el arte centroamericano. Posteriormente, en el segundo, se examina un corpus de noticias recopilado sobre el suceso para determinar por qué las reacciones son distintas en ambos países. En términos metodológicos se realizó un análisis hemerográfico de la prensa costarricense: Excélsior, La Nación, La República, La Prensa Libre, Diario Uno, Semanario Universidad y The Tico Times. Para el caso guatemalteco se revisó: El Gráfico, La Hora, El Imparcial, El Impacto, El Diario de Centroamérica y La Prensa Libre. Además, se revisaron los documentos referidos a "Arte latinoamericano" y "Arte centroamericano" en el acervo del International Center for the Arts of the Americas (ICAA) documentos del Museo de Houston. 
Palabras clave Certamen artístico; crítica de arte centroamericano; pintura centroamericana; arte moderno centroamericano; crítica de arte.

Abstract The article analyzes the reactions caused by the jury's decision on the First Central American Painting Biennial in 197I, in both the Costa Rican and Guatemalan press. In the first section, Marta Traba's position on Central American art is contextualized. Subsequently, in the second section a corpus of news articles compiled on the event is examined, to determine why the reactions were different in the two countries. In methodological terms, a hemerographic analysis was carried out on the following Costa Rican newspapers: Excelsior, La Nación, La República, La Prensa Libre, Diario Uno, Semanario Universidad, and The Tico Times. Press reviewed for Guatemala: El Gráfico, La Hora, El Imparcial, El Impacto, El Diario de Centroamérica and La Prensa Libre. In addition, documents referring to Latin American and Central American Art were reviewed in the archive of ICAA documents of the Houston Museum.

Keywords Art contest; Central American art critic; Central American painting; Central American modern art; art critic. 
DOI: https://doi.org/10.22201/iie.18703062e.2021.119.2763

\author{
SOFÍA VINDAS SOLANO
}

UNIVERSIDAD DE COSTA RICA

\title{
La I Bienal Centroamericana de Pintura y la presencia de Marta Traba en la prensa costarricense y guatemalteca, 1970-1979
}

، Toy a mencionar a una persona verdaderamente detestada en Costa Rica, que es Marta Traba", ${ }^{\text {r }}$ éstas son las palabras con las que interviene el crítico de arte Carlos Francisco Echeverría en un panel organizado por el periódico La Nación, sobre la situación del arte costarricense en 1975, cuatro años después de lo acaecido en la Bienal de Pintura de 197I en ese país. Dicho certamen lo convocó el Consejo Superior Universitario Centroamericano (CsUCA), liderado por el entonces secretario general del organismo, el escritor nicaragüense Sergio Ramírez. La Bienal fue auspiciada por el Ministerio de Cultura, Juventud y Deportes de Costa Rica y la comunidad de escritores costarricenses.

Convocada en Costa Rica en 1971, la Bienal abrió el concurso a todos los países de la región, lo cual era una práctica usual en Centroamérica en los certámenes de este tipo desde décadas anteriores. Esto sucedió, por ejemplo, con la consolidación de los conocidos "Certámenes is de septiembre". Según Virginia Pérez Ratton, esta Bienal,

I. "No existe verdadera cohesión en la plástica costarricense", La Nación XXIX, núm. I3, secc. Suplemento Áncora, 5 de enero, 1975, 4. 


\section{DOI: https://doi.org/10.22201/iie.18703062e.2021.119.2763}

se concibe de forma visionaria, como una bienal de artes, en plural —se incluyen encuentros de escritores, lecturas de poesía, música y danza. Este carácter multidisciplinario, actualmente moneda corriente en este tipo de eventos, era inédito para la época en gran parte del mundo, y en lo que respecta al contexto del istmo, "arte" o "artista" hasta hace poco se manejaban como únicamente sinónimos de "pintura" y "pintor".

Cada uno de los países centroamericanos participantes en la Bienal en I97I realizó una selección previa de artistas concursantes, por medio de las instituciones nacionales familiares al sector de las artes, a saber, las direcciones generales, las escuelas de artes plásticas, entre otros. En el caso de Guatemala las obras las escogieron el rector de la Universidad San Carlos (USAC), Rafael Cuevas del Cid, el arquitecto Jorge Montes Córdova, el ingeniero Américo Giracca y el conocido arquitecto y escritor Lionel Méndez Dávila, quien fue jefe de la Dirección General de Bellas Artes y que para entonces fungía como director de Extensión Universitaria en la USAC. Dávila había sido también cofundador de la importante revista Alero, proyecto editorial de esa universidad.

Para realizar la selección de los premiados se invitó, como jurados, a la crítica de arte Marta Traba (Argentina, 1930-1983), a los artistas: José Luis Cuevas (México, 1934-20I7), Fernando de Szyszlo (Perú, 1925-2017), Armando Morales (Nicaragua, 1927-20II) y Oswaldo Guayasamín (Ecuador, 1919-1999). Estas personas eran, para finales del siglo $\mathrm{xx}$, personalidades destacadas del arte regional y promotores globales del arte moderno latinoamericano (fig. I). En la categoría de pintura se entregaría un gran premio centroamericano, así como otro por país participante. Una vez revisadas las postulaciones, el acta del veredicto se publicó en varios medios locales, entre ellos el periódico costarricense La Nación (fig. 4). El documento del jurado decía:

I. Ha sido preocupación permanente del jurado emitir un fallo que además de tener en cuenta la calidad objetiva de las obras tomara en consideración su significado dentro del contexto nacional y latinoamericano [...] el jurado ha tratado de estimular [...] aquellas búsquedas que muestran simultáneamente una asimilación del lenguaje contemporáneo de la pintura con la urgencia de expresar

2. Virginia Pérez Ratton, “¿Qué región? Apuntando hacia un estrecho dudoso”, en eds. Víctor H. Acuña Ortega, Alexandra Ortiz Wallner y Dominique Ratton Pérez, Pérez-Ratton: travesía por un estrecho dudoso (San José, Costa Rica: TEOR/éTica, 20I2), 48. 


\section{Los mejores pintores de Centroamérica}

Los mejores pintores de los países centroamericanos presentarán sus mejores obras en el concurso de pintura que auspicia el Consejo Superior Universitario Centroamericano .... . . (CSUCA) para conmemorar los 150 años de vida libre en América Central.

La bienal de pintura ha quedado abierta y para el mes de setiembre se producirá en nuestro país la exposición de los trabajos participantes, los cuales se exhibirán en el Teatro $\mathrm{Na}$ cional al mismo tiempo que se efectúa el Concurso Centroame. ricano de Teatro. En esa oportunidad se destinará un salón especial para exhibir obras de los autores consagrados de la América Central.

Los nombres de pintores que intervienen en la bienal fueron dados a conocer ayer por el ... CSUCA y son los iguientes:

\section{GUATEMALA}

Marco Augusto Quiroa

Roberto Cabrera

Elmar René Rojas

Efraín Recinos

Arnoldo Ramírez Amaya

Rodolfo Mishaan

Rolando Ixquiac Xicará

Luis Díaz.

\section{NICARAGUA}

Armando Morales

Rolando Castellón

Rodrigo Peñalba

Omar de León

Alejandro Aróstegui
Orlando Sobalvarro

Jenaro Loug

Róegr Pérez de la Rocha

\section{EL SALVADOR}

Carlos Cañas

Camilo Minero

Mario Escobar

Roberto Huezo

Armando Solís

Víctor Barrier

Víctor Manuel Rodríguez Presa

Antonio Garca Ponce

\section{COSTA RICA}

Rafael Fernández

Arq. Rafael Angel García

Luis Darll

Lola Fernández

César Valverde

Jorge Manuel Vargas

Jorge Gallardo

Ricardo Monales

\section{HONDURAS}

Benigno Gómez

Luis H. Padilla

Juan Ramón Laínez

Arturo López Rodezno

Mario M. Castillo

Miguel Angel Ruiz Matute

Moisés Becerra

Alvaro Canales

\section{SALON DE HONOR}

Carlos Mérida, (México)

J. Antonio Velásquez (Honduras)

Teodorico Quirós (Costa Rica)

Manuel de la Cruz González, (Costa Rica)

Francisco Amighetti R. (Costa Rica).

I. "Los mejores pintores de Centroamérica", La Nación, XXIV, 8044, 24 de mayo de I97I, 58. Biblioteca Nacional, Costa Rica. 
DOI: https://doi.org/10.22201/iie.18703062e.2021.119.2763

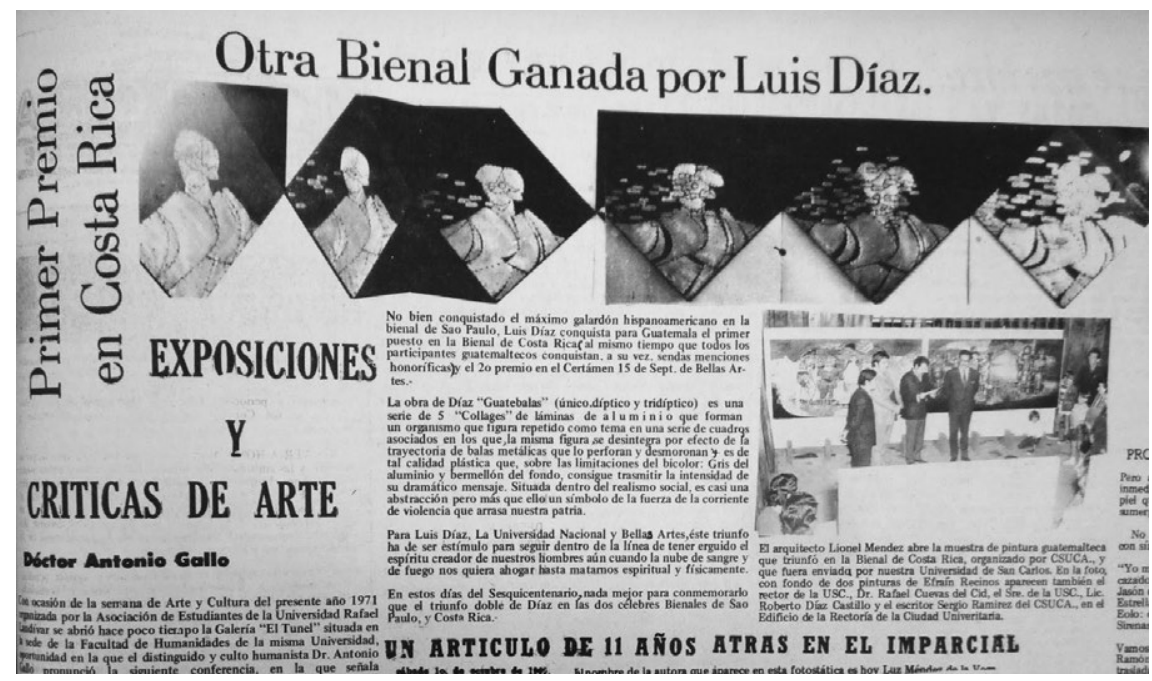

2. “Otra Bienal Ganada por Luis Díaz”, La Hora, IV, 87II, I8 de septiembre de I97I, 3. Hemeroteca Nacional, Guatemala.

contenidos que revelan la situación del artista en su medio y la honesta necesidad de comunicarlo.

2. De acuerdo con estos principios el jurado por unanimidad, resuelve: Declarar desierto el premio nacional de Costa Rica, porque la participación de este país a pesar de presentar un aceptable nivel técnico en los casos de Lola Fernández, Rafael Fernández y Jorge Manuel Vargas, tiene un empleo superficial de recursos ya empobrecidos por el uso excesivo (collage de fotografías, pistola de aire, frottage, etc.). ${ }^{3}$

Adicionalmente a estas declaraciones, el fallo del jurado le otorgó ${ }^{4}$ el galardón centroamericano a la obra del artista guatemalteco Luis Díaz (I939), titulada Guatebala (1970) (fig. 2), hoy desaparecida; por otro lado, Rolando Castellón (1937) obtuvo el premio por Nicaragua con su obra Danza alegórica (1970), un dibujo al carboncillo. Como hemos visto, de acuerdo con el acta, el jurado declaró desiertos los premios nacionales de casi todos los países. En el caso de

3. "Guatemala ganó I Bienal de Pintura Centroamericana", La Nación, vol. XXIV, núm. 8I59, secc. Nacionales, I6 de septiembre de I97I, 25.

4. "Guatemala ganó I Bienal de Pintura Centroamericana", 25. 


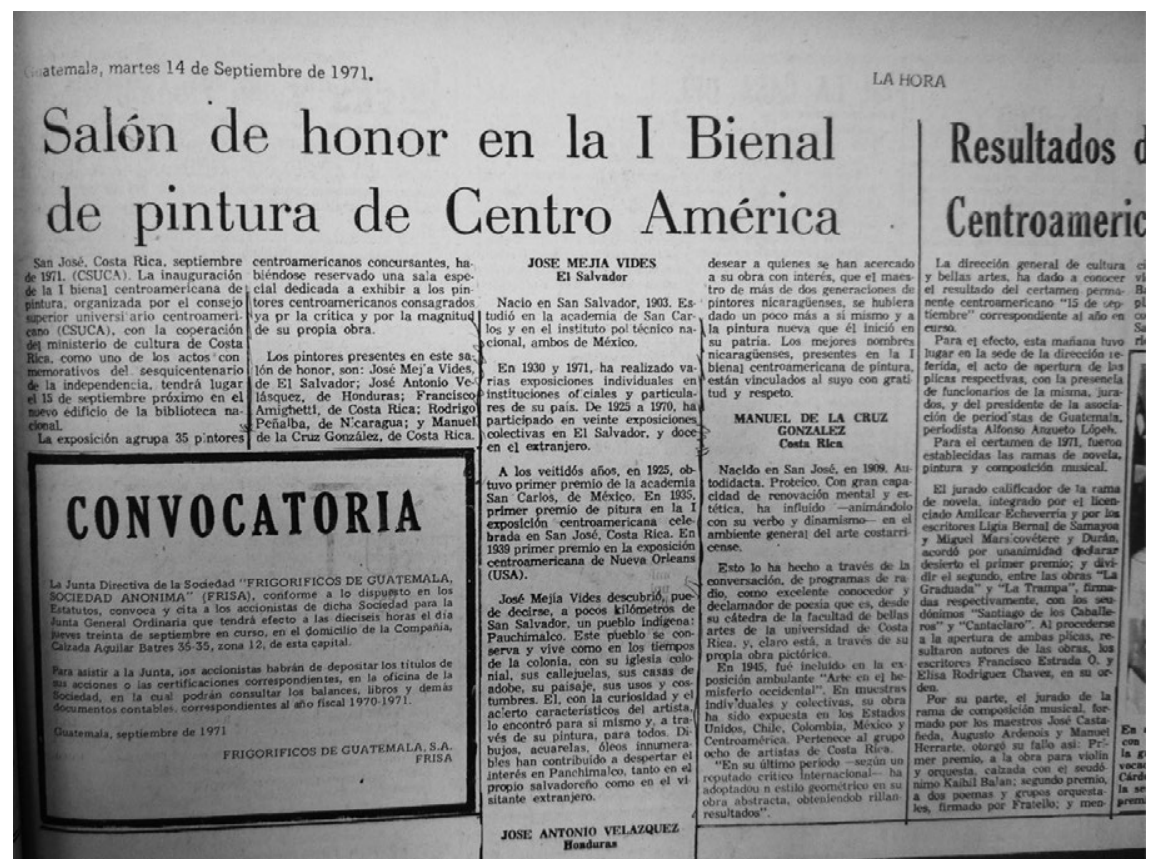

3. "Salón de honor en la I Bienal de pintura Centroamericana”, La Hora, IV, 8707, I4 de septiembre de 1971, 7. Hemeroteca Nacional, Guatemala.

El Salvador se declaró desierto, "porque ninguna de las obras presentadas llena los requisitos para merecerlo, por su carencia de imaginación y bajo nivel técnico". 5 En el caso de Honduras la mayoría de las obras demostraba ser "ajenas al proceso del arte contemporáneo", y en Costa Rica también se declaró desierto, por el empleo "superficial de recursos ya empobrecidos" en las obras. Se destacaron únicamente las obras de Francisco Amighetti (1907-1998) y Manuel de la Cruz González (1909-1986), quienes fueron invitados al Salón de honor en representación de Costa Rica, en nombre de El Salvador se invitó a José Mejía (1903-1993), a Rodrigo Peñalba (1908-1979) de Nicaragua y de Honduras se convocó a José Antonio Velázquez (1906-1983) (fig. 3).

Las dos obras ganadoras desaparecieron: tanto la de Díaz como la de Castellón. Según el nicaragüense, ${ }^{6}$ su obra fue robada, y al día de hoy se conserva

5. "Guatemala ganó I Bienal de Pintura Centroamericana”, 25.

6. Doriam Díaz, "Rolando Castellón: el hacedor de las I3 vidas", https://www.nacion.com/ 


\section{DOI: https://doi.org/10.22201/iie.18703062e.2021.119.2763}

sólo una copia. Con relación a la desaparición de estas obras, parece que estos sucesos no generaron mayor revuelo ${ }^{7}$ en la prensa, puesto que en los periódicos la cobertura del certamen se centró en comunicar el fallo y polemizarlo.

La Bienal tuvo diversos tipos de alcances en el gremio artístico en la región. Esta investigación analiza estas reacciones, e inicia con una lectura de lo debatido en los periódicos del país anfitrión (Costa Rica) y del país ganador (Guatemala). Se ha centrado el análisis en el caso costarricense puesto que, como se verá, fue ahí donde se generó un debate sostenido a lo largo de la década de los ańos setenta sobre lo sucedido en el concurso, mientras que en Guatemala el tono con el que se cubrió la noticia fue celebratorio.

No se ha estudiado el debate en torno a la Bienal de i97ı a la luz de lo que estaba sucediendo entonces en el contexto de la internacionalización del arte latinoamericano. Las décadas de los años sesenta y sesenta son consideradas por diversos autores como el punto cúspide en la consolidación de una noción de "arte latinoamericano". Por una parte, críticos de arte como Marta Traba, Jorge Romero Brest, Nelly Richard, Juan Acha, entre otros, encabezaron una corriente de pensamiento que aportó líneas discursivas centrales al entendimiento del arte de esta región, que lograron posicionarlo desde la crítica de arte en la palestra cultural internacional. Por otra parte, en cuanto al mercado, para finales de los años setenta las altas ventas de arte moderno latinoamericano, en casas de subastas como Sotheby's, ${ }^{8}$ indicaban que el arte de Latinoamérica era codiciado y podía ser un motor de la economía de alcance transnacional.

En dicho contexto, el análisis del caso de esta Bienal nos permite reconocer entre otras cosas, cómo se manifestaron las tensiones latentes en la configuración de esa noción de lo que era o debía ser el arte latinoamericano, en la

viva/cultura/rolando-castellon-el-hacedor-de-las-I3-vidas/3HUBGMHO6FGQ5MNZDZAX6A7Q4I/ story/ (consultado el I3 de mayo de 20I8).

7. Sobre esto Luis Fernando Quirós afirma: "Un acto como ése, que desaparecieran obras de tal categoría hoy en día sería un escándalo de implicaciones diplomáticas; no tuvo tanta trascendencia, pero sí rencillas ante la decisión del jurado de no otorgar premios a El Salvador, Honduras y a Costa Rica", véase Luis Fernando Quirós-Valverde, "Discontinuidad y contradicción”, https://wsimag.com/es/arte/37744-discontinuidad-y-contradiccion (consultado el 3 de mayo de 20I8).

8. Como ejemplo de ello, en una nota de los años ochenta, la Revista Américas analiza la gran relevancia que había alcanzado la venta del arte latinoamericano para finales de la década de los años setentas. Véase Verónica Gould Stoddart, "Latin American Art Market Booms", Revista Américas 34, núm. 5 (1982): 52. 
región centroamericana. Aunque de manera marginal, el arte de Centroamérica se incluyó en esta construcción de una estética latinoamericana, sin embargo, participó en ella como periferia de un área geográfica ya de por sí periférica.

Es por esto que la Bienal deja ver cómo se posicionaron los actores locales frente a las negociaciones que se dieron en la época en relación con las modernidades estéticas del arte de Centroamérica, inscritas en el área geopolítica más amplia del arte latinoamericano. En la discusión suscitada por el suceso en Costa Rica y Guatemala podemos encontrar algunas pistas sobre cómo estos países leyeron las ventajas o debilidades de su producción artística, a la luz del juicio impartido en 1971 por exponentes fundamentales del arte latinoamericano. Además, en el ámbito gremial, al medir las reacciones de la comunidad asociada a las artes visuales en ambos países, podemos sopesar las ramificaciones locales institucionales que parece haber tenido el acontecimiento. Por ejemplo, algunas investigaciones han sugerido que en el caso costarricense la Bienal influyó en la consolidación del Museo de Arte Costarricense entre 1977 y 1978.

Para resolver estas inquietudes y determinar cuáles fueron los ejes de la discusión en la prensa a raíz de la Bienal, el artículo se divide en los siguientes apartados: primero se analiza qué se ha dicho en Costa Rica sobre este concurso de 1971, en seguida se aborda un apartado titulado "Marta Traba y la crítica del arte latinoamericano: ¿dónde está Centroamérica?”, en el cual se rastrea la postura de Traba sobre el arte latinoamericano y la región de Centroamérica para contextualizar su conocimiento del arte de esta zona. Es importante centrarnos en la figura de la crítica argentino-colombiana, porque al menos en la prensa costarricense, y según los recuentos de testigos, ella fungió como "vocera" del jurado de la Bienal; asimismo en la prensa, es contra ella y sus posturas teóricas que se dirigen las críticas referentes al veredicto del certamen.

En la segunda parte se aborda el recibimiento del fallo del jurado de la Bienal de Pintura de 197I en la prensa costarricense y guatemalteca. Este apartado corresponde a un estudio del corpus de noticias recopilado sobre el suceso en la prensa entre 1970-1979. Para el caso costarricense, la controversia se dio principalmente en torno a cuatro ejes de discusión: el primero tiene que ver con lo que la prensa argumentó sobre conformación, calidad y validez del jurado del certamen; el segundo revisa la postura de algunos interlocutores(as) que encuentran, en el fallo de la Bienal, una oportunidad de mejoramiento del medio artístico local; el tercero tiene que ver con los comentarios en torno al tratamiento de "lo político" en la pintura local, y el cuarto revisa un debate 


\section{DOI: https://doi.org/10.22201/iie.18703062e.2021.119.2763}

sobre la identidad latinoamericana frente a la costarricense, en un intento de artistas de este país por entender la crítica que el jurado realizó de la escena cultural nacional.

Para el caso guatemalteco, la cobertura de la Bienal da cuenta de una lectura bastante homogénea de lo sucedido: la prensa publicó notas con tono de celebración de los triunfos de los artistas de este país, debido a que el ganador del certamen, el artista Luis Díaz, recién había recibido otros galardones, entre ellos en la XI Bienal de Sao Paulo en 197I.

En términos metodológicos, para realizar esta revisión se consultaron los siguientes periódicos del periodo 1970-1979: Excélsior, La Nación, La República, La Prensa Libre, Diario Uno, Semanario Universidad, y The Tico Times. Todos estos documentos están disponibles digital o físicamente en la Biblioteca Nacional de Costa Rica, el Semanario Universidad está en la Biblioteca Tinoco de la Universidad de Costa Rica. Para el caso guatemalteco se revisaron los periódicos El Gráfico, El Imparcial, El Impacto, La Hora, Diario de Centroamérica y La Prensa Libre los cuales se consultaron en la Hemeroteca de la Biblioteca Nacional de Guatemala. Además, se revisaron los documentos referidos a Arte Latinoamericano y Centroamericano en el acervo de los ICAA docs del Museo de Houston sobre Marta Traba. En futuras investigaciones sobre el tema, este análisis se puede complementar con una revisión de lo discutido en las revistas culturales de la época en estos países, porque sin duda en esos espacios debió darse un intercambio fructífero sobre este tipo de sucesos.

\section{¿Qué se ha dicho sobre la Bienal?}

La historiografía del arte centroamericano ha analizado poco la Bienal de I97I. En Costa Rica las investigaciones sobre lo sucedido en 197I han comenzado a aparecer apenas hace unos 5 o Io años aproximadamente. En su mayoría, estos estudios han discutido las implicaciones estéticas que tuvo la decisión del jurado en el país anfitrión. Algunos autores han planteado, como se verá más adelante, que el fallo del evento se interpretó como una reacción contra las tendencias de la pintura abstracta costarricense, lo que propició la aplastante irrupción de los lenguajes neofigurativos en el país posterior al suceso. Éste es el caso de las investigaciones de autores como Guillermo Montero y Mauricio Oviedo. Otros estudiosos como Luis Fernando Quirós y Virginia Pérez Ratton han hecho una lectura de los tejidos sociales intervenidos por el proceso, 
y han sopesado las tensiones culturales entre países y las implicaciones del fallo en el ámbito artístico de la región.

Por otra parte, Roberto Cabrera, Gabriela Sáenz Shelby y Pablo Hernández han subrayado también las repercusiones políticas e institucionales que tuvo el certamen para Centroamérica, y sugieren que fueron los choques culturales como el vivido en la Bienal del 7I, los que alentaron a los países centroamericanos a profesionalizar sus gremios artísticos, al perfilar la creación de los museos de arte moderno en Centroamérica, y consolidar políticas culturales que trabajaran en pos de mejorar el arte de la región. Otros estudios mencionan de manera algo más tangencial el suceso, entre ellos están los textos de José Miguel Rojas.

La investigación más reciente es "Antecedentes a la posición de Marta Traba con relación a la Bienal Centroamericana de 1971"9 de Klaus Steinmetz. En este texto, el autor mapea el entramado teórico del pensamiento de Traba de manera que sea posible comprender mejor en lo que estaba trabajando la crítica de arte para entonces, y contextualizar así la postura que tuvo en la Bienal (fig. 4). El presente estudio se nutre de todos estos trabajos, puesto que el debate que se encontró en la prensa trastoca todas estas temáticas, es decir, desde las tensiones sobre lo estético, el contexto sociocultural, así como la postura teórica del jurado, en particular en relación con la crítica, Marta Traba.

La presente revisión contribuye a la relectura del suceso en la historia de arte centroamericano, para no sólo evidenciar las líneas discursivas en torno a la controversia y sobre la situación contemporánea del arte en Costa Rica y Guatemala de finales del siglo $\mathrm{xx}$, sino también para contraponer estos elementos a las tensiones subyacentes a los debates en torno a la construcción, en dicha época, de una noción de arte latinoamericano que incluía a Centroamérica.

\section{Marta Traba y la critica del arte latinoamericano: ¿dónde está Centroamérica?}

La crítica colombiano-argentina fue una protagonista central de los interesantes debates que se dieron a lo largo del siglo xx, en torno a la construcción de

9. Klaus Steinmetz, "Antecedentes a la posición de Marta Traba con relación a la Bienal Centroamericana de I971”, en María José Monge Picado, coord., Congreso sobre creación artística en la década de 1970 (San José, Costa Rica: Fundación Museos Banco Central de Costa Rica, 2019), 63-67. 


\section{El fallo de la Primera Bienal}

El veredicto del jurado de la Primera Bienal de Pintura Centroameride las celebraciones del Sesquicentena-
rio de nuestra Independencia, es a rio de nuestra Independencia, es a
nuestro juicio, si se saben mirar bien nuestro juicio, si se saben mirar bien las cosas, altamente beneficioso para para el quehacer estético y literario del país. Esa decisión de un jurado cuya competencia e imparcialidad no parecen admitir dudas, toda vez que
fue integrado por valores latinoamericanos reconocidos, nos abre los ojos ante la realidad de nuestra cultura. tes, de esos que siguen la tendencia mundo $\mathrm{y}$ de no entrarles a fondo a las cosas, puede hacer daño no solamente a la pintura costarricense, sino novela y a otras manifestaciones arte que han tomado en los últimos años, entre nosotros, mucho impulso. jurado compuesto por criticos y pintores extranjeros, sin conexiones con los expositores, adjudica únicamente dos premios: uno para el pintor guapintor nicaraguiense Rolando Castellón y declara, con un rigor poco común aquí, desiertos los demás.

Bien sabemos que hay en el pais pintores con excepcionales dotes, $y$ una gran inquietud por las artes plásticas.
Pero con la pintura nuestra está pasan con la literatura mos el sentida, que a veces perdeTenemos que evitar que los juegos florales se conviertan en instituciones de prórliga convistan en instituciones de cias a jurados que de premios, graas influencias y parlamentos con ante e les acosa antes de su fallo a favor ésta o la otra persona. La decisión del jurado de la PriLa decision de Pintura que de la Pride eliminar no debe que nos acaba que, por el contrario, debe significo para todos los pinto, debe significar un desafio, y sobre pleno en el sentido todo un despertar trabajar col sentado de que hay que dad, sobre todo autenticidad, y conticilabor de crítica autenticidad, y con una inclineión tea menos indulgente. Esa de dar al taste a quedar bien puenuestra literste con nuestra plástica y que se conceden. Esa facilidad con nes para ceden premios y distincioen muchos pictoricas y literarias, pero en otras con justificadamente, nos puede llevar a unifiesta largueza, cidez y desventaj a una posición de flaciones desventaja frente a otras nacomposición por tener una diferente dia - son mós rial - menos clase meFste más riguroso

Este fallo debe servir de punto de juegos para que nuestros concursos y critica lorales asuman una posición crítica más severa.
4. "El fallo de la Primera Bienal", La Nación XXIV, 8160, I7 de septiembre de I97I, I4. Biblioteca Nacional, Costa Rica.

una idea de lo que era el arte latinoamericano. Autores como Gabriela Piñero, Fabana Serviddio, Cuauhtémoc Medina, entre otros, han indagado ampliamente en su trabajo para entender el pensamiento de Traba y su evolución a lo largo de su trayectoria como gestora, curadora y crítica de arte. Investigaciones como éstas han evidenciado que su postura sobre el tema tuvo dos momentos claros de cambio. Primero entre 1945 y la década de 1960, cuando Traba adoptó un punto de vista de corte eurocéntrico, ya que tomó como referencia al arte moderno europeo. Después, a partir de I960-1965 en adelante cuando, "dándose cuenta del peligro que representa la internacionalización de las artes latinoamericanas, empieza a defender un arte moderno latinoamericano, que refleje o respete las identidades culturales regionales". ${ }^{\circ}$

Por su parte, Gabriela A. Piñero ha estudiado la manera en que otros críticos de arte, como ella, matizaron su pensamiento sobre el arte de esta región,

ıo. Elsa Crousier, "De Europa a América: la obra crítica de Marta Traba y sus evoluciones”, Artelogie, núm. I5 (2020), I. 


\section{DOI: https://doi.org/10.22201/iie.18703062e.2021.119.2763}

primero al vincularlo a una idea de "arte americano" de las primeras décadas del siglo xx, y posteriormente al insertarse en la construcción de una noción de "arte latinoamericano", consolidado en la segunda mitad de ese siglo. Estos cambios tuvieron que ver de forma paralela con la necesidad de caracterizar la particularidad de la región y su situación geopolítica, ante el contexto que atravesaba Latinoamérica en la época, con el recrudecimiento de la intervención extranjera en la región durante la Guerra Fría. Esta lectura geopolítica de intelectuales como Traba, también estuvo influida por una lectura crítica de los postulados de la teoría de la dependencia, entre otros. De esta manera,

el tránsito entre una y otra categoría, y lo que ese tránsito registra, puede pensarse con relación a la coyuntura mayor (política, económica) que acompañó el devenir de la región y su inscripción a escala internacional [...] y los años de 1970 cuando Traba esgrime la bandera latinoamericanista, la región dejó de encarnar la utopía del progreso y bienestar, para revelar su condición marginal y secundaria en el reparto económico global."

En su concepción sobre lo que era el arte de la región, Traba aseguró que había que luchar contra una noción de "americanismo" radical, puesto que su defensa podría resultar ${ }^{12}$ en un errado nacionalismo continental, tan "nefasto" como los nacionalismos regionales. Para ella, el arte latinoamericano debía entenderse como una gran familia, una que poseía rasgos en común y elementos distintivos, pero todos diferentes expresiones. La autora trató de defender esa multiplicidad de voces en el arte, haciendo la salvedad de que:

es posible que invocar el americanismo sea un deseo de provincianos nacidos de un complejo de inferioridad por nuestra falta evidente de cultura o un concepto falsamente romántico [...] pero también es posible que esta expresión no tenga nada de colectivo, puesto que las condiciones económicas, geográficas y culturales son muy distintas de un país a otro en América; es posible que se trate de una expresión individual..$^{13}$

II. Gabriela A. Piñero, "El tránsito entre el proyecto de un 'arte americano' (I920-1930) y la fórmula de un 'arte latinoamericano' (1950-1970)”, A Contracorriente: Revista de Historia Social y Literatura en América Latina II, núm. 2 (2014): 20.

I2. Marta Traba, “¿Qué quiere decir un arte americano?”, Mito I, núm. 6 (1956): 478.

I3. Traba, "¿Qué quiere decir un arte americano?”, 477. 


\section{DOI: https://doi.org/10.22201/iie.18703062e.2021.119.2763}

En esta segunda fase del pensamiento de Traba, el estudio del arte desde una óptica de lo geopolítico fue central. Sobre esto, Cuauhtémoc Medina ha dicho que los textos que produjo Traba en los años setenta fueron trascendentales en nuestra historia regional, por haber sido análisis hechos desde América Latina sobre la repercusión de la globalización en el contexto artístico regional, su imbricada relación con la economía y su impacto en el devenir plástico de Latinoamérica.

Más allá de ello, en su pensamiento sobre lo que era el arte latinoamericano, pensadores como Traba hicieron esfuerzos para incluir en sus escritos a la región centroamericana. Hacia principios de la década de los años setenta, en la prolífica obra de la autora el arte de esta zona está presente, aunque de manera tangencial.

Sin duda, para críticos como Traba, fue importante acercarse a Centroamérica e integrarla al estudio del arte latinoamericano, ya que, en esta construcción de una noción de arte regional, era crucial evidenciar la multitud de voces y formatos producidos por los artistas, incluyendo la zona de América Central y el Caribe. Después de todo, Latinoamérica no podía estar completa si no era tomada en cuenta la zona central del continente.

Si bien la trayectoria de Traba estaba bastante comprometida con la promoción de artistas sudamericanos, un elemento para entender el lugar marginal que ocupó Centroamérica en su trabajo, es que Traba había visitado poco la región. Entre 1970-1971 había pasado un tiempo como profesora invitada en la Universidad de Puerto Rico, ${ }^{14}$ por lo que estaba familiarizada con el arte de la zona del Caribe.

De hecho, el tema sobre su lejanía con Centroamérica aparece en la prensa de la época, como sucedió en el periódico La República. Ahí, el periodista

I4. Según el acervo documental de textos sobre arte latinomamericano del Museo de Bellas Artes de Houston, la relación de Traba con el Caribe data de la década de los años setenta. "A partir de agosto de 1970 hasta el verano de 197I, la Universidad de Puerto Rico, Recinto de Río Piedras, la contrató para dictar un curso de arte latinoamericano amén de los cursos Teoría general de historia del arte (20I) e Historia del arte moderno (213), entre otros, en el Departamento de Bellas Artes. En el verano de 197I ofreció un curso de Estética. Al finalizar el verano, la Universidad no le renovó el contrato. Durante su residencia en Puerto Rico, Traba escribió libros y muchos artículos en la prensa y en revistas, en los cuales planteó su posición frente al arte puertorriqueño. Fueron motivo de numerosos cuestionamientos y críticas entre la clase artística", en Marta Traba, "La pintura como medio de comunicación", en: https://icaa. $\mathrm{mfah.org/s/es/item/823772} \mathrm{(consultado} \mathrm{el} \mathrm{I3} \mathrm{septiembre} \mathrm{de} \mathrm{2019).}$ 


\section{DOI: https://doi.org/10.22201/iie.18703062e.2021.119.2763}

LA I BIENAL CENTROAMERICANA DE PINTURA

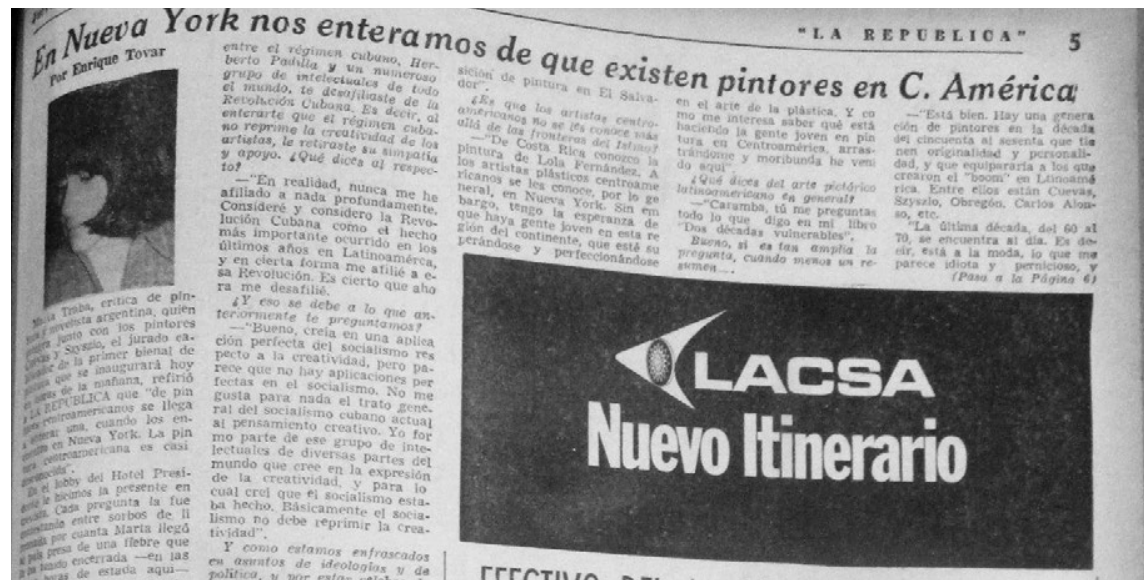

5. "En Nueva York nos enteramos de que existen pintores en C. América", La República, vol. XX, 6609, I6 de septiembre de I97I, 5. Biblioteca Nacional, Costa Rica.

Enrique Tovar le consultó a Traba “¿Por qué no se menciona un artista costarricense en 'Dos décadas vulnerables'?", is a lo que la autora contestó: "En cuanto a la pintura costarricense, tengo muy poco criterio porque no la conozco, y en general de toda Centroamérica. Ésta es la segunda vez que vengo al istmo. Hace pocos años asistí a una exposición en El Salvador" (fig. 5). Por eso en 197I, cuando junto con los demás miembros del jurado participó de la Bienal de Pintura, Traba manifestó expresamente su deseo de utilizar la oportunidad para conocer el "arte joven de la región". ${ }^{16}$

La exposición a la que hace referencia Traba en esa nota, es el Certamen de Cultura de El Salvador que se había efectuado en 1967. Dicho acontecimiento fue también un certamen de artes plásticas, cuyo concurso estuvo abierto a los países de la región incluidos Panamá y Belice. En 1967 Traba participó como jurado allí, junto a Oswaldo Guayasamín y José Luis Cuevas, quienes regresaron con ella en 197I a la Bienal de Pintura de Costa Rica. El Boletín de Artes Visuales de la Organización de Estados Americanos registróo ${ }^{17}$ el suceso, y

I5. Éste es un famoso texto de Traba que estaba por publicarse en I973, aunque ya existía otro libro muy conocido de ella titulado Los cuatro monstruos cardinales, publicado en 1965.

16. Tovar, "En Nueva York nos enteramos de que existen pintores en C. América".

17. "El Salvador, Certamen de Cultura”, Boletín de Artes Visuales I7, núm. II (1967): 47. 


\section{DOI: https://doi.org/10.22201/iie.18703062e.2021.119.2763}

302

SOFÍA VINDAS SOLANO

señaló que el primer premio lo ganó Constanza Calderón (1937) de Panamá y el segundo lugar fue para la obra Nejab (1967) de la artista guatemalteca Margarita Azurdia (I93I-I998), o bien Margot Fanjul, su seudónimo en dicha época.

Fruto de estos acercamientos que logró realizar Traba con Centroamérica, se puede apreciar en Hombre americano a todo $c o l o r,{ }^{18}$ el libro que pretendió publicar en 1975, pero que finalmente difundió la Universidad Nacional y el Museo de Arte Moderno de Bogotá en 1995. En dicho texto, Traba presentó un análisis más detallado de algunos artistas centroamericanos, como el nicaragüense Armando Morales (1927-20II), mientras que, de Guatemala, comentó la obra de Rodolfo Abularach (1933) y Luis Díaz (1939). De igual manera, revisó el trabajo de Agustín Fernández (1928-2006), de Cuba, y Francisco Rodón (1934), de Puerto Rico. Su experiencia en la Bienal de 1971, sin duda, también le aportó elementos para su siguiente libro más importante: Arte de América Latina: 1900-1980, publicado de manera póstuma en 1994 por el Banco Interamericano de Desarrollo. En dicho texto, hacia la década de los ańos ochenta y antes de su fatídica muerte en un accidente aéreo, Traba ya había cultivado un más consolidado conocimiento sobre Centroamérica.

Para entonces, en sus textos menciona a artistas centroamericanos para ejemplificar casos exitosos de trabajo artístico moderno. Por ejemplo, en este último libro habló sobre la fuerza con que renacieron el grabado y el dibujo en los años sesenta en la región; asimismo mencionó que Centroamérica dio buenos ejemplos de expresionismo abstracto ${ }^{19} \mathrm{y}$ produjo interesantes exploraciones estéticas en la geometría. ${ }^{20} \mathrm{~A}$ razón de ello, hizo especial mención del arte guatemalteco y nicaragüense.

Para principios de los años setenta en cambio, si bien en los textos de Traba hay una mención ocasional a artistas de la zona centroamericana, no hay una construcción teórica profunda más allá de la clasificación que la autora hizo de la zona como una "área cerrada". ${ }^{21}$ Es decir, un grupo de países "donde predominan las condiciones endogámicas, la clausura, el peso de la tradi-

I8. Marta Traba, Hombre americano a todo color (Bogotá: Editorial Universidad Nacional/ Uniandes, 1995).

19. Marta Traba "Las décadas emergentes", en Arte de América 1900-I980 (Washington D.C.:

Banco Interamericano de Desarrollo, I994), 88.

20. Traba, "Las décadas emergentes", II2.

2I. Junto con Bolivia, Colombia, Perú, Ecuador, Paraguay y el Caribe. 
ción, la fuerza de un ambiente". ${ }^{22}$ La clasificación hecha por Traba sobre las "áreas abiertas" y "áreas cerradas" se estableció, "a partir de la apertura y permeabilidad que cada una de estas regiones (que funcionaban como conglomerados de países) poseía en relación con las corrientes artísticas y culturales del norte, es decir, a partir de la mayor o menor vinculación de cada región con "el modelo del desarrollo capitalista". ${ }^{23}$

Esta lectura geopolítica de Traba, en relación con las tendencias estéticas latinoamericanas, es central, ya que el fallo de la Bienal de 197I ha sido entendido ampliamente como un rechazo a la abstracción costarricense, puesto que algunas de las obras participantes emplearon este lenguaje, también algunos de los artistas participantes por parte de Costa Rica eran conocidos como importantes exponentes de la abstracción en el ámbito local. Según algunos investigadores, el rechazo del jurado propició en el país "el impulso más fuerte de retorno a la figuración, así como el frente de oposición a las tendencias no figurativas que habían penetrado el arte de América Latina". ${ }^{24}$ Para autores como Mauricio Oviedo, el dictamen de la Bienal develó que "el jurado ansiaba [...] una producción plástica que estuviese envuelta en el contexto artístico contemporáneo, pero que ofreciera resistencia a los lenguajes artísticos originarios de los centros hegemónicos, de forma que se apropiase críticamente de las herramientas que le resultasen necesarias". ${ }^{25}$

En este sentido, más que una reacción en contra o a favor de un lenguaje estético, interesa echar un vistazo a partir del caso de la Bienal, al complejo contexto en el que se estaban negociando identidades y modernidades en el arte latinoamericano en espacios como estos concursos, públicos y privados, en Centroamérica. En estos eventos las y los artistas de la región se enfrentaron a una discusión sobre su lugar en la palestra del arte latinoamericano, y sobre su capacidad para aportar a las narrativas del arte regional desde acá. Por ello, debemos tener en cuenta, según lo ha explicado Gabriela Piñero, que

22. Marta Traba, Dos décadas vulnerables en las artes plásticas latinoamericanas, 1950-1970 (Buenos Aires: Siglo XXI, 2005), 92.

23. Cuauhtémoc Medina, "El último refugio del arielismo", ponencia presentada en Marta Traba y las batallas del arte en Latinoamérica, XI Cátedra Internacional de Arte Luis Ángel Arango, Bogotá, 2006.

24. Guillermo Montero, "La I Bienal de Pintura Centroamericana”, Káñina 36, núm. 3 (2012): 86 .

25. Mauricio Oviedo, "La entrada de la neofiguración a Costa Rica por parte de 'los cuatro monstruos cardinales' de Marta Traba", Artes-UNICACH 9, núms. I-2 (2015): I6-27. 


\section{DOI: https://doi.org/10.22201/iie.18703062e.2021.119.2763}

304

SOFÍA VINDAS SOLANO

para Traba las obras latinoamericanas más interesantes eran aquellas que se adecuaban a la "peculiar noción del tiempo dentro del cual vive Latinoamérica" ${ }^{26}$ por lo que, para ella, "fue fundamental una concepción de lo artístico que postulaba un fuerte vínculo entre las obras y sus sociedades productoras y receptoras, y que primó en los años sesenta y setenta”. ${ }^{27}$

\section{El fallo del jurado de la I Bienal de Pintura: entre la controversia costarricense y la celebración guatemalteca}

La Bienal de Pintura de 197I formó parte de una Bienal de Artes Centroamericana visionaria, ya que para la época los eventos de esta índole se caracterizaron por convocar certámenes por género artístico: es decir, de escultura, grabado, literatura, poesía, entre otros. Con pocos antecedentes, esta Bienal ${ }^{28}$ invitó a concursar a artistas de todos los géneros en certámenes individuales. Ésta fue la primera que lo hiciese, junto con la Bienal Coltejer de Medellín, Colombia de 1968. Por otro lado, fue una de las primeras bienales de tipo regional, aunque le anteceden entre otras la Bienal de Sao Paulo que inicia en I95I.

Como vimos, la actividad fue organizada por el csuCA, en el marco del II Festival Cultural Centroamericano. Paralelamente se organizó un Encuentro de Escritores Centroamericanos. ${ }^{29}$ Según una nota de prensa en el Diario de Centroamérica en Guatemala, la Bienal fue "un esfuerzo de primera magnitud en el campo de la cultura que lleva efecto el consejo superior universitario centroamericano". ${ }^{\circ}$

Se presentaron al certamen 42 pintores de los cinco países del área de América Central. El premio centroamericano de pintura contaría con una dotación

26. Gabriela A. Piñero, "Territorialidad, localía y derivas de lo político en América Latina: crítica de arte y escritos de artistas", AURA. Revista de Historia y Teoría del Arte, núm. iI (I3 de septiembre de 2020): IO.

27. Piñero, "Territorialidad, localía y derivas de lo político en América Latina”, ıo.

28. Es importante recordar la "Exposición Centroamericana" de Guatemala de 1987, la cual consistió en una feria industrial y cultural internacional, así como la "Primera Exposición Centroamericana de Artes Plásticas", en 1935 en Costa Rica.

29. "Encuentro de Escritores en el Festival Cultural Centroamericano", El Gráfico, vol. IX, núm. 2591, secc. Nacionales, 3 de septiembre de 1971, I7.

30. "Bienal Centroamericana de Pintura", Diario de Centroamérica, vol. XCI, núm. 27186, secc. Nacionales, 6 de septiembre de 197I, 8. 
de 3,000 dólares, así como con la entrega de una medalla. El premio nacional recibiría Iooo dólares para cada país que lo ganara, con su respectiva medalla de plata. Para el crítico de arte Luis Fernando Quirós, el éxito que tuvo el concurso en términos de convocatoria, tuvo que ver con que no fue un "evento oficial organizado por algún ente ministerial o gobierno del área, sino por un organismo universitario autónomo con sede en el país" ${ }^{31}$

El contexto en el que este certamen sucedió es clave: había dictaduras y guerras en toda América Latina, y una alta conflictividad social después de mayo de 1968. El triunfo de la revolución cubana, en los años cincuenta, había acrecentado las tensiones geopolíticas, y la necesidad de control sobre Latinoamérica y Centroamérica por parte de los Estados Unidos. Estas problemáticas se dieron en el marco de una inminente crisis capitalista internacional y de una "reorientación del capitalismo mundial bajo una incipiente hegemonía neoliberal". ${ }^{32}$ Costa Rica no fue ajena a esta realidad: por ejemplo, para la época, el movimiento estudiantil había estado luchando durante los primeros meses de 1970, haciéndole frente al proyecto de explotación minera de la empresa Alcoa en el país. Por otra parte, en el plano cultural, numerosos artistas regresaban al país luego de haber recibido becas para estudiar en el extranjero, "por ejemplo, el artista Juan Luis Rodríguez, quien se integró a la Universidad de Costa Rica en la Escuela de Artes Plásticas de la Facultad de Bellas Artes". ${ }^{33}$

Por su parte, en Guatemala, desde la década anterior, se habían instaurado, lo que Edelberto Torres Rivas llama "democracias de fachada": gobiernos militares altamente represivos, organizados con "el ritual de siempre, una asamblea constitucional, una nueva constitución y elecciones presidenciales”. ${ }^{34}$ Así llegó al poder Julio César Méndez (1966-1970), único civil en llegar a la presidencia entre 1950 y 1986, quien se autodesignó como el líder del "tercer gobierno de la Revolución de Octubre" cuando fue en realidad el primero de varios gobiernos de las llamadas "democracias de fachada", que se extenderían hasta los

3I. Luis Fernando Quirós, "X Bienal Centroamericana 2016 Autopistas del siglo XxI”, Revista Hoja Filosófica núm. 40 (junio de 20I6): 25.

32. Jorge Rovira Mas, "Edelberto Torres Rivas: la perspectiva centroamericana”, en Edelberto Torres Rivas, Centroamérica: entre revoluciones y democracia, Colección Pensamiento Crítico Latinoamericano (Bogotá, Colombia: ClaCso, 2008), 23.

33. Montero, "La I Bienal de Pintura Centroamericana".

34. Edelberto Torres Rivas, La piel de Centroamérica: una visión epidérmica de setenta y cinco años de su historia (Guatemala: FLACSO, 2006), IO2. 


\section{DOI: https://doi.org/10.22201/iie.18703062e.2021.119.2763}

306

SOFÍA VINDAS SOLANO

años ochenta. En 1971 le sucede en el poder el militar Carlos Manuel Arana Osorio (1970-1974), conocido como "El Carnicero de Zacapa”, quien llegó a:

manejar la concentración de guerrilleros alrededor el área de Zacapa, ubicada en el este de Guatemala, de la manera más brutal. Indiscriminadamente matando a civiles y guerrilleros en masa... Los escuadrones, solo nominalmente separados del gobierno, también contribuyeron a la brutal represión de las fuerzas de oposición. La aparente violencia generalizada de izquierda y derecha fomentó una cultura de miedo. Así, cuando Arana Osorio se postuló para presidente, la plataforma más obvia que vendería sería una de ley y orden..$^{35}$

En este contexto de alta efervescencia social se celebró la Bienal de Pintura de 1971. Con relación a la discusión en prensa a raíz del fallo del jurado logré constatar cuatro categorías de debate para el caso costarricense a lo largo de la década de los años setenta. A saber:

- La primera con relación a la validez de la conformación del jurado del certamen. Esta discusión se da de manera más inmediata después del fallo del jurado en los meses posteriores a septiembre de i97I.

- La segunda sobre el fallo de la Bienal como oportunidad de mejoramiento: estos artículos toman una postura de aceptación de la situación. En general ésta fue una respuesta contradictoria en algunos casos, en los cuales se manifestó descontento con el veredicto, pero se hizo un intento por no disentir con el mismo. Los artistas y críticos de arte nacionales (en su mayoría hombres) aceptaron el veredicto a regañadientes como oportunidad de fortalecer los procesos de producción artística, entre ellos la institucionalidad del arte nacional.

- La tercera tuvo que ver con la naturaleza de "lo político" en el arte y el debate de la abstracción versus la neofiguración, así como en las temáticas que deberían representar los artistas. Este punto versa en un malentendido de los conceptos de Traba, en especial sobre su crítica a la abstracción y el papel del arte, así como la pintura como "medio de comunicación”.

35. Damon Pichoff, “'Acribillados y torturados': Newspapers and the Militarized State in Counterrevolutionary Guatemala", tesis de maestría en Historia (Gainesville: Universidad de Florida, 2007), 3-4. 


\section{DOI: https://doi.org/10.22201/iie.18703062e.2021.119.2763}

LA I BIENAL CENTROAMERICANA DE PINTURA

- La cuarta y última tuvo que ver con la noción de la identidad latinoamericana frente a la costarricense, y cómo se reflejó esta discusión en la plástica. Esta temática se dio en prensa entrada la década de los años setenta, cinco años después del evento, una vez que la Bienal era una anécdota. A continuación, se analiza cada una de las categorías de debate.

\section{Sobre la conformación del jurado}

Los debates sobre el jurado del certamen se dieron de inmediato en la prensa, después del veredicto publicado en septiembre de i97i. El peso de la crítica se dirigió casi en su totalidad hacia Marta Traba. Estas reacciones tuvieron dos tendencias: por un lado, se descalificó el veredicto del jurado en general por considerarse radical, pero, por otro, hubo un intento de acoplarse al fallo del jurado. En especial, algunos críticos de arte costarricenses adoptaron la teoría de Traba de sus libros y sus declaraciones en prensa, para apropiarse de la fuerte lectura que realizó el jurado del arte costarricense, y así hacer eco de sus preocupaciones sobre la mediocridad de las propuestas artísticas locales. La mayoría de los artículos encontrados como respuesta a la Bienal aparece dos meses después del fallo, o sea en noviembre de i97I.

Por ejemplo, el artista César Valverde (1928-1998) escribió en ese mes un artículo titulado "Bienal..., bien mal!" En general la nota es conciliatoria, aunque el artista adoptó una postura contradictoria. Valverde, quien había participado en el concurso, afirmó aceptar la responsabilidad de lo que se le criticó, explicando que él consideraba que no había trabajado con dedicación ${ }^{36}$ en su propia obra, titulada Picasso y el Tercer Mundo (197I). El cuestionamiento al veredicto del concurso lo dejó para el final del artículo, al poner en duda la capacidad de los integrantes del jurado para decidir sobre la calidad de las obras; eso lo explicó así: "El jurado estaba formado en su mayoría por pintores, quizás en esto estriba el error, pues como me decía un buen amigo, 'cuando se va a hablar de peces... nunca para juzgar a los peces debe buscarse a otros peces"' (fig. 6). ${ }^{37}$

36. A razón de esto el artista dice: "Reconozco mi falla o si se quiere, mi irresponsabilidad, pues para cumplir con el compromiso contraído, trabajé con toda prisa y sin mucha dedicación”. Véase César Valverde, “Bienal..., bien mal!”, La Nación, vol. XXIV, núm. 8218, secc. Opinión, I4 de noviembre de I97I, I5.

37. Valverde, "Bienal..., bien mal!", I5. 


\section{DOI: https://doi.org/10.22201/iie.18703062e.2021.119.2763}

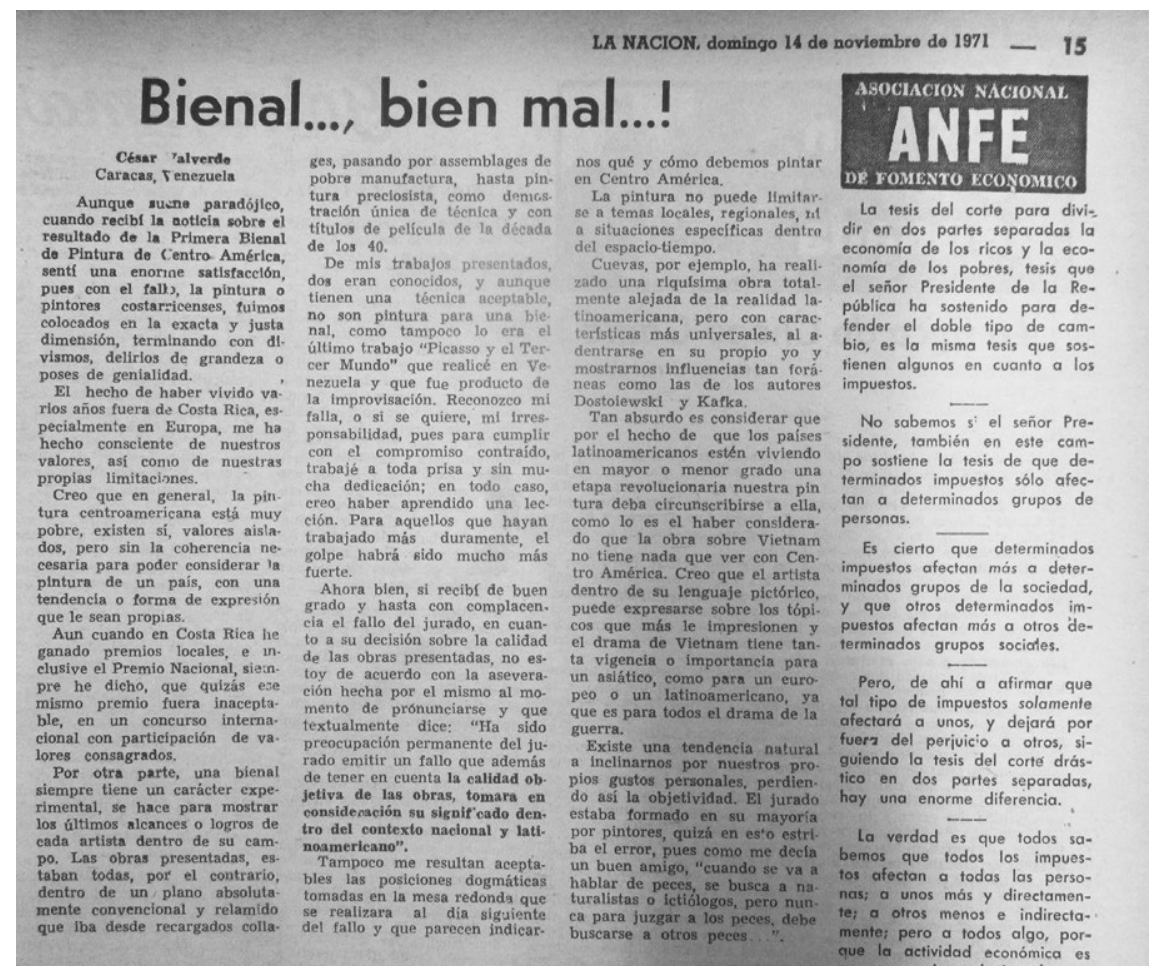

6. “Bienal..... bien mal!”, La Nación, XXIV, 8218, I4 de noviembre de 1971, I5. Biblioteca Nacional, Costa Rica.

En cambio, columnistas como Alfonso Chase criticaron severamente cada una de las obras costarricenses que participaron en la Bienal; esto lo hizo Chase en las páginas del Semanario Universidad, diario de la Universidad de Costa Rica. Sobre la pieza Supervivencia (197I) de Lola Fernández, Chase dijo que, "En esta oportunidad lola [sic] se dejó tentar por la facilidad y nos da cuadros bien tratados técnicamente, pero cuyo contenido y mensaje se pierden con la inclusión de elementos ajenos a su propia pintura" ${ }^{38}$ Con este comentario Chase se ajusta a lo que el fallo del jurado había dicho, a saber: Lola Fernández había sido hábil en su técnica, pero su obra no brindaba un contenido claro y contundente.

38. Alfonso Chase, "Costa Rica en la primera Bienal de Centroamérica", Semanario Universidad, vol. 2, núm. 44, 8 de noviembre de 1971, IO. 


\section{DOI: https://doi.org/10.22201/iie.18703062e.2021.119.2763}

LA I BIENAL CENTROAMERICANA DE PINTURA

Con esta línea crítica Chase continuó el análisis de otras obras. De la obra de Rafa Fernández, Los anticuarios (I97I), afirmó: "A pesar de su estética, no dice nada. Es la belleza por la belleza, en un plano superficial, pero de gran don técnico". ${ }^{39}$ Sobre el artista Jorge Vargas, y la Gran estructura blanca (197I) dijo: "Presentada con dignidad se queda en eso: una estructura que cumple su función prepictórica, de diseño y disposición agradable, pero que no dice nada, o que más bien dice todo, esto es no tener nada que decir" (fig. 7). ${ }^{40}$

\section{El fallo como una oportunidad de crecimiento}

Con relación a este eje, encontramos que los artistas costarricenses y otras personalidades manifestaron, no sin protestar, la necesidad de ver en la decisión del jurado una oportunidad para el crecimiento del arte de ese país. Valverde ya había dicho en la nota arriba mencionada que al enterarse del fallo: "sentí una enorme satisfacción, pues con el fallo los pintores costarricenses, fuimos colocados en la exacta y justa dimensión, terminando con divismos, delirios de grandeza o poses de genialidad", ${ }^{4}$ aunque recordemos que, en su artículo, acto seguido descalifica al jurado.

En una editorial, el periódico La Nación publicó una nota optimista que decía: "El veredicto del jurado de la Primera Bienal de Pintura Centroamericana es, a nuestro juicio, altamente beneficioso para la plástica costarricense, y en general para el quehacer estético y literario del país [...] nos abre los ojos ante la realidad de nuestra cultura." ${ }^{22}$ La nota continúa señalando que la calidad de los miembros del jurado era evidente, y que las protestas que habían surgido del grupo dejaba ver la cultura complaciente del típico crítico "criollo" costarricense, quien "sigue la costumbre muy tica de quedar bien con todo el mundo y de no entrarle a fondo a las cosas". ${ }^{43}$

Casi un año después de la Bienal, Rafael "Rafa" Fernández (I935-2018) manifestó a la prensa su desacuerdo con la postura del jurado. En la historia

39. Alfonso Chase, "Costa Rica en la primera Bienal de Centroamérica", Semanario Universidad, vol. 2, núm. 44, 8 de noviembre de 1971, Io.

40. Chase, "Costa Rica en la primera Bienal de Centroamérica".

4I. Valverde, "Bienal..., bien mal!", I5.

42. "El fallo de la Primera Bienal", La Nación, vol. XXIV, núm. 8160, secc. Editorial, i7 de septiembre de 197I, I4.

43. "El fallo de la Primera Bienal", I4. 
DOI: https://doi.org/10.22201/iie.18703062e.2021.119.2763

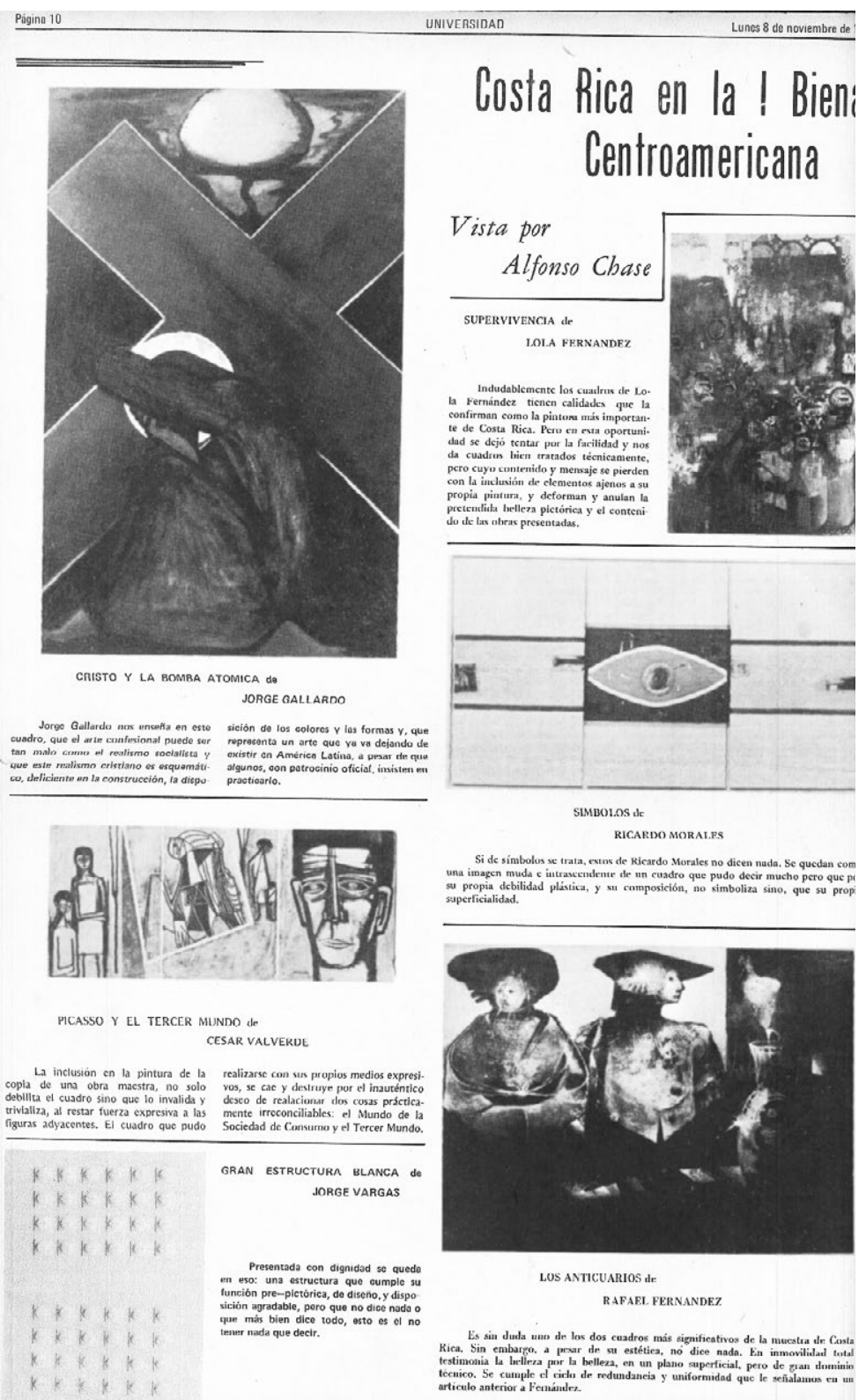

7. "Costa Rica en la I Bienal de Centroamérica", Semanario Universidad, 2, 44, 8 de noviembre de 1971, Io. Biblioteca Luis Demetrio Tinoco, Costa Rica. 
oral local alrededor de este suceso, se ha contado la anécdota de que en la inauguración de la Bienal, en la Biblioteca Nacional de Costa Rica, Rafa Fernández (quien era boxeador) le comenzó a lanzar puñetazos a José Luis Cuevas, durante la lectura del veredicto del jurado. Este tema, sin duda, no se mencionó cuando se le entrevistó para la nota "El realismo mágico de Rafa Fernández". En esa ocasión un periodista le preguntó: “¿Qué importancia dio Rafa Fernández a las decisiones del Jurado de la Primera Bienal Centroamericana de Pintura?", a lo que respondió Fernández:

esos fallos influyeron positivamente en nuestro ambiente artístico, porque precipitaron la definición de valores nacionales. Algunos fueron golpeados muy fuertemente y parece ser que aún no se han superado. Otros, al contrario, nos afirmamos en nuestros conceptos y aceptamos lo constructivo de la crítica dejando a un lado la palabrería de una Marta Traba o un José Luis Cuevas. ${ }^{44}$

Así, este artista, que participó en el certamen, expresó la necesidad de ver en dicho acontecimiento una oportunidad de crecimiento para el arte costarricense. Sin embargo, en su respuesta hace referencia no sólo al impacto negativo de la Bienal en el medio artístico, sino que también descalifica él mismo la argumentación del jurado, al denominarla como "palabrería". Estas opiniones, en definitiva, parecen ser conciliadoras, pero no proponen vías para problematizar qué era exactamente lo que había que mejorar en el arte de Costa Rica.

\section{Sobre lo politico en el arte costarricense}

Con relación a la crítica del contenido de las obras participantes en esta Bienal, existen varias opiniones en la prensa. Un ejemplo es el artículo del escritor costarricense José Marín Cañas, titulado errónea y sarcásticamente: "María Traba". En este texto, el autor atacó con fuerza a la crítica colombiano-argentina, al afirmar que la lectura del jurado cayó en una radicalidad absurda, puesto que se limitó a premiar el arte comprometido y el arte político por moda. Cańas argumentó que, por el contrario, el buen arte no necesariamente debía hacer referencia a un contexto político, y señaló: "ahora está de moda

44. Mariamalia Sotela Berrocal, "El realismo mágico de Rafa Fernández", La Prensa Libre, vol. 82, núm. 22492, secc. Nacionales, I7 de julio de 1972, I4-I5. 


\section{DOI: https://doi.org/10.22201/iie.18703062e.2021.119.2763}

ser un artista comprometido... ¿por qué los pintores, para subsistir, deben afiliarse al movimiento de 'guerrilla pictórica' para poder valorizar su obra?" 45 Además, en su comentario aludió a que el fallo de la Bienal, de manera injusta, premió a las obras con fuertes contenidos políticos, y ésa era la razón por la que Guatemala había ganado el premio centroamericano.

Ante lo anterior, es importante revisar las obras sometidas al certamen por parte de los y las artistas costarricenses (fig. 7). La mayoría de las piezas representaron, de diversas maneras, situaciones de violencia, la efervescencia cultural y la problemática social. En el caso de Lola Fernández, la artista presentó la obra Sobrevivencia (197I), la cual aborda la difícil transición industrial y tecnológica que vivía Centroamérica en ese tiempo, además de reflejar importantes aspectos de ese contexto como la aceleración del consumo y la cultura de masas, y hechos como la guerra de Vietnam, entre otros. Por su parte, César Valverde presentó, como se dijo antes, la obra Picasso y el Tercer Mundo (1971), y Jorge Gallardo una obra titulada Cristo y la bomba atómica (197I). Al parecer, en estas propuestas artísticas existe una intención evidente por mostrar una trama política en las obras o al menos una lectura sociopolítica del contexto local e internacional. Entonces, ¿por qué es que los críticos y comentaristas como Cañas, argumentan que el jurado "injustamente", pidió que el arte costarricense hiciera un comentario político? Si se analizan estas propuestas, muchas de hecho representaban aspectos del contexto convulso en el que fueron producidas, entonces ¿no era eso lo que buscaba Traba, según los críticos de la prensa costarricense? (fig. 8).

Marta Traba con seguridad conocía los cuestionamientos que se realizaban en su contra, ya que meses después del veredicto envió desde Caracas un artículo que se publicó en el diario La Nación en noviembre de 197I, en el que ampliaba lo sucedido en la Bienal, titulado "Por qué Guatemala se tragó la Bienal". ${ }^{46}$

En el texto Traba afirmaba que la razón por la que Guatemala había ganado el concurso, no era por ser arte "panfletario" o arte producido en situaciones de guerra: "No quiero hacer la inferencia simplista de que una situación dramática, donde la vida se juega cada día en medio de terribles ten-

45. José Marín Cañas, "A propósito de María Traba”, La Nación. vol. XXIV, núm. 8222, secc. Comentarios, I8 de noviembre de I97I, I5.

46. Marta Traba, "Por qué Guatemala se tragó la Bienal", La Nación, vol. XXIV, núm. 82I4, secc. Comentarios, II de noviembre de I971, I5-16. 


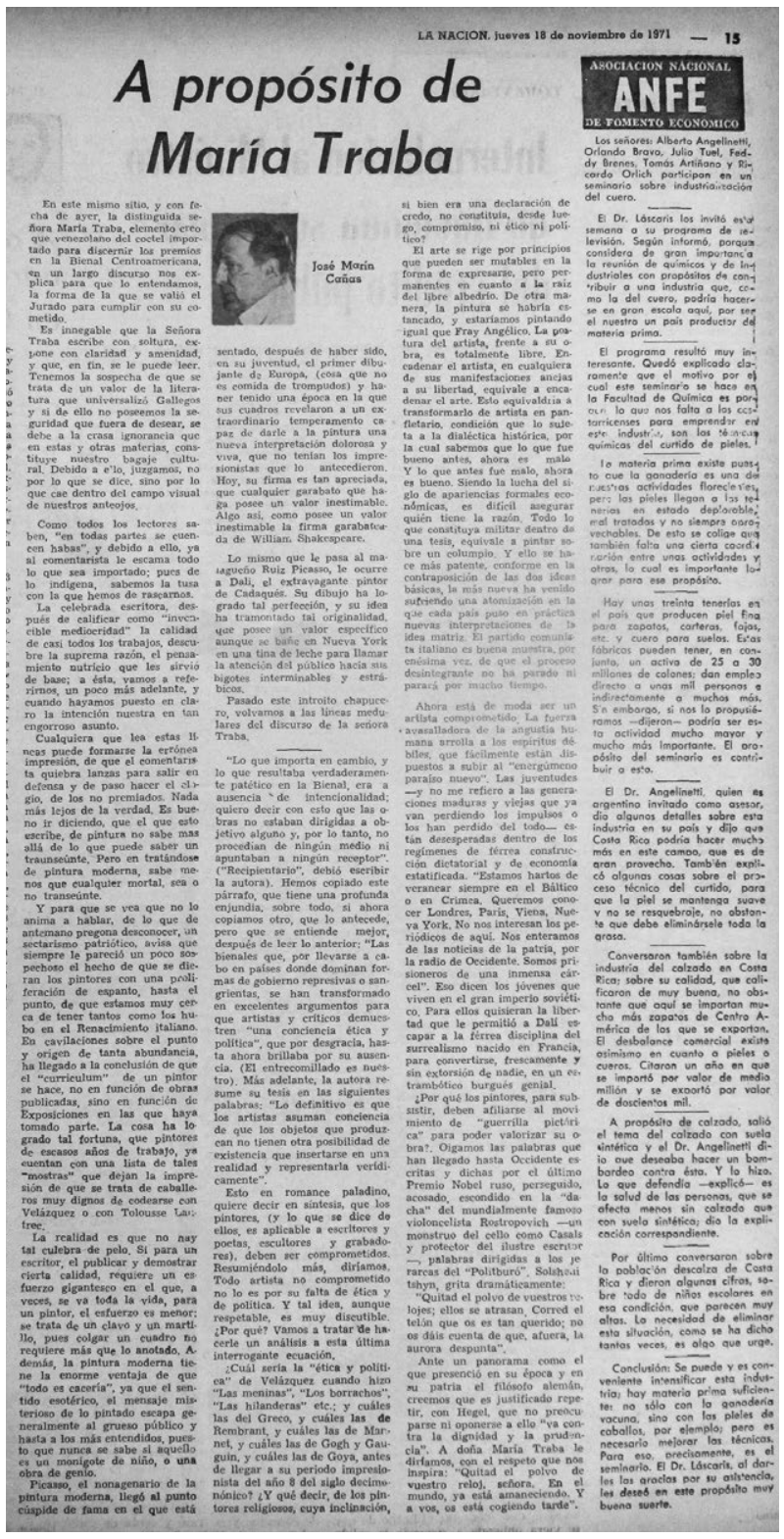

8. "A propósito de María Traba", La Nación, XXIV, 8222, I8 de noviembre de 197I, I5. Biblioteca Nacional, Costa Rica. 


\section{DOI: https://doi.org/10.22201/iie.18703062e.2021.119.2763}

siones debe crear un arte importante y válido; pero sí es indudable que de un volcán en erupción salen torrentes de lava ardiendo” ${ }^{47}$ A pesar de sus observaciones, varios comentaristas hicieron un esfuerzo en la prensa por reducir la visión de "lo político" en Traba, a aquel arte comprometido o que denuncia situaciones de injusticia, o bien un arte panfletario.

Años después, en una entrevista de 1976 que le realizó Renato Cajas Corsi para el periódico costarricense Excélsior,$^{48}$ el periodista le preguntó cuál era el camino certero que debía seguir el arte para ser relevante, y agregó a su cuestionamiento: "¿puede por ejemplo hacerse arte relevante mediante un lenguaje tan criticado como el paisajismo?”, Traba respondió:

puede ser o no el paisajista. Lo importante es que lo que se haga, toque a nuestro hombre... Puede ser de cualquier naturaleza: puede ser político (por supuesto no panfletario ni de partido), sino político en el sentido amplio del término, relacionado al medio, prestando aporte positivo al papel del arte como formación de conocimiento. ${ }^{49}$

En estas interacciones se nota cómo Traba intentó ampliar su postura con relación al contenido del arte producido en el ámbito local.

De regreso a septiembre de 1971, el periodista Enrique Tovar le preguntó a Traba por qué su postura era tan contundente con la generación de artistas de la segunda mitad del siglo xx, a ello la crítica le contestó: "Porque es idiota plagiar. Estos pintores latinoamericanos copian principalmente a los norteamericanos [...] no hablemos con eufemismos. Digamos las cosas con claridad."

En esta respuesta es interesante ver que Traba generaliza la situación que encontró en la Bienal, un problema extendido en el arte latinoamericano de la época. Con estas palabras hacía referencia a su pensamiento en torno a la estética del deterioro, ${ }^{\text {SI }}$ es decir: un arte prefabricado, desechable, efímero, que se

47. Marta Traba, "Por qué Guatemala se tragó la Bienal", I5-I6.

48. Esta entrevista en Excélsior en noviembre de 1976, se da por motivo de la visita de Marta Traba al país para dar una serie de charlas sobre arte universal y arte latinoamericano en el Colegio Costa Rica, invitada por la Editorial eduCA.

49. Renato Cajas Corsi, "Arte actual cola de león en vez de cabeza de ratón”, Excélsior, vol 3, núm 67I, secc. 2, I de noviembre, 1976, 3.

50. Enrique Tovar, "En Nueva York nos enteramos de que existen pintores en C. América", La República, vol. XX, núm. 6609, secc. Nacionales, I6 de septiembre de 1971, 5-6.

51. Sobre la obra de Traba, Angie Montiel Muñoz analiza que "la estética del deterioro es, al mismo tiempo, ecuación y resultado de un proceso de alienación de los sujetos sociales, quienes 
producía en los contextos de las sociedades de consumo masivo. Un arte sintomático de las sociedades globalizadas, por lo que "no alude sólo a un estado de crisis del arte occidental, sino a un nuevo modo de aculturación imperialista impuesto por la gran metrópoli y ejecutado gracias al altísimo nivel de penetración de los medios masivos de comunicación". s2 $^{2}$

Traba parece haber intentado esclarecer las razones que dieron lugar a la polémica por medio de estas entrevistas, en las que enfatizó que el arte centroamericano se limitaba a hacer una reproducción de lenguajes copiados de capitales artísticas, como Nueva York, problemática extendida a toda la región latinoamericana. Sobre esto señaló que el problema no era el género o estilo del arte que se hiciera, sino la intencionalidad del arte centroamericano lo que había marcado la diferencia en 1971. Y agregaba: "hacer expresionismo, hacer pop o geometría abstracta, hacer informalismo, por la simple razón de que se hace (o se hizo) en los centros emisores, no podía pasar de pobres imitaciones, parodias muertas o insignificantes"..$^{3}$

En ese mismo artículo de 1976 , la crítica de arte recuperó la centralidad de su postura, a saber, la importancia de la finalidad o el propósito de la obra artística. Este tema lo había elaborado también en la ponencia que leyó en Costa Rica en 1971, en el marco de la inauguración de la Bienal. En esa ocasión se refirió a la importancia del papel de la comunicación en la pintura. Al respecto, Traba explicó categóricamente que:

Lo que importa, en cambio, y lo que resultaba verdaderamente patético en la Bienal era la ausencia de intencionalidad; quiero decir con esto que las obras no estaban dirigidas a objetivo alguno [...] Resultaban ejecutadas porque sí, respondiendo sólo a la distracción personal de los artistas y a su mayor o menor capacidad de resolver la pintura como un problema técnico. Las pinturas eran por consiguiente objetos flotantes..$^{54}$

consumen ideológica y materialmente los productos del arte fascinados con la promesa del deleite entretejido en la diversión y liberación de nunca acabar, ya que, sin problema, estos productos son reemplazados como cualquier otra mercancía de la industria cultural", en Angie Gloriela Montiel Muñoz, "El legado de Marta Traba: reflexiones teóricas en torno a la creación artística en América Latina 1983-2003”, ESCENA. Revista de las Artes 76, núm. I (2017): 91.

52. Facundo Enrique Gómez, "Interpretar, discutir, orientar: Marta Traba y la crítica de artes latinoamericana”, Anales de la Universidad Central del Ecuador I, núm. 374 (2016): 74.

53. Marta Traba, "Por qué Guatemala se tragó la Bienal", I5.

54. Cajas Corsi, "Arte actual cola de león en vez de cabeza de ratón”, 3. 


\section{DOI: https://doi.org/10.22201/iie.18703062e.2021.119.2763}

$3 \mathrm{I} 6$

SOFÍA VINDAS SOLANO

Es claro que a la autora le preocupaba el tema del acceso a la información y a la cultura de masas, pues lo comentó en la entrevista de 1976. Sobre esto, dijo: "el principal problema, sin embargo, es que este quehacer continúa siendo una producción que llega a un grupo muy pequeño [...] Entonces pierden su vigencia y su razón de ser. Y si no tienen razón de ser no son artes". "s Ante esto, Renato Cajas Corsi insistió: “¿Entonces ese arte no tiene ningún valor?”, a lo que ella contestó: "Puede que lo tengan desde un punto de vista de la crítica formal. Desde el punto de vista de la sociología no tiene valor." ${ }^{56}$

\section{Sobre el debate en torno a la identidad local frente al arte latinoamericano}

El último eje sobre el debate que suscitó el fallo del jurado tuvo que ver con el contenido y la identidad de la plástica costarricense. Como se ha visto, la contundencia del veredicto también motivó la apropiación local de la lectura que realizó Marta Traba y el resto del jurado sobre el arte centroamericano, en especial con relación a los criterios teóricos expresados en sus publicaciones. A razón de esto, la autora colombiano-argentina volvió a aparecer en la prensa en 1975 en un panel titulado nada más y nada menos: "No existe verdadera cohesión en la plástica costarricense." ${ }^{7}$

En la nota, los interlocutores desarrollaron una discusión interesante propuesta por Antonio Yglesias, cineasta tico, quien consideró pertinente analizar la noción de la identidad y las motivaciones tras los mensajes plásticos de los artistas costarricenses. ${ }^{8}$ En el debate, Carlos Francisco Echeverría -el ya mencionado crítico de arte costarricense, quien llegaría a ser ministro de Cultura entre 1986 y 1990-, abrió su intervención mencionando el resentimiento que aún tenía el medio costarricense hacia Marta Traba. Y dedicó casi la totalidad de su participación a explicar la teoría contenida en el libro Dos décadas vulnerables, para analizar la situación del arte en Costa Rica a la luz de estos postulados teóricos.

Echeverría expuso los conceptos de "arte de resistencia”, "zonas abiertas y cerradas”, ante un panel compuesto por pintores (Felo García, Luis Daell,

55. Cajas Corsi, "Arte actual cola de león en vez de cabeza de ratón", 3.

56. Cajas Corsi, "Arte actual cola de león en vez de cabeza de ratón", 3.

57. "No existe verdadera cohesión en la plástica costarricense", La Nación, vol. XXIX, núm. I3, secc. Suplemento Áncora, 5 de enero, 1975, 4-5.

58. "No existe verdadera cohesión en la plástica costarricense", 4-5. 
Carlos Martínez y Juan Luis Rodríguez) y dos críticos de arte, Antonio Yglesias (cineasta) y él mismo. Una vez que terminó de explicar la teoría de Traba, los panelistas parecieron ignorar sus comentarios y se enfrascaron en una discusión propuesta por Yglesias, que interpelaba lo dicho por Echeverría. A continuación, se reproduce el intercambio: ${ }^{59}$

Antonio Yglesias: Yo me atrevería casi a arriesgar una tesis no muy novedosa [...] en forma de pregunta: ¿han existido en Costa Rica verdaderas corrientes espirituales, motivaciones que liguen y creen realmente una plataforma espiritual, poética que haya proporcionado [...] un verdadero tipo de expresión pictórica? Al no existir esto probablemente lo que existe es un deseo constante de agarrarse o de aranar situaciones exteriores que probablemente tuvieron su forma natural, su cuna espontánea y que en nuestro país pierden su paternidad [...].

Felo García: Lo de Antonio es interesante porque siempre se ha debatido muchísimo si un medio ideal es un medio como el nuestro, de gran placidez, en donde las situaciones no exigen lucha [...] yo no sé si esa falta de estímulo para continuar en esa actitud agresiva nos ha puesto en una situación de placidez, en donde el arte como que se ha endulzado un tanto.

Juan Luis Rodríguez: El desconocimiento de nuestra propia cultura trae como consecuencia la no identificación y situación del artista nacional [...] ¿Cómo va a haber un terremoto espiritual si no tenemos nociones de lo que está anteriormente?

Resulta interesante cómo en esta intervención, los comentaristas parecen referirse al texto "Por qué Guatemala se tragó la Bienal", sobre todo la última intervención de Rodríguez. Estos tres comentarios también evidencian una crítica al medio costarricense, y establecen un debate sobre el lugar del arte nacional en lo local y su incapacidad de insertarse más ágilmente en la escena internacional.

Los dialogantes parecen estar de acuerdo en que el problema del gremio costarricense radicaba en el desconocimiento de su propia historia y la poca problematización de la memoria local. Como resultado, algunos artistas costarricenses habían aplicado la estrategia de copiar tendencias estéticas y temáticas extranjeras, para hacerse un espacio en el panorama del arte latinoamericano. Es decir, habían reproducido arte que representaba lecturas acríticas

59. "No existe verdadera cohesión en la plástica costarricense", 4-5. 


\section{DOI: https://doi.org/10.22201/iie.18703062e.2021.119.2763}

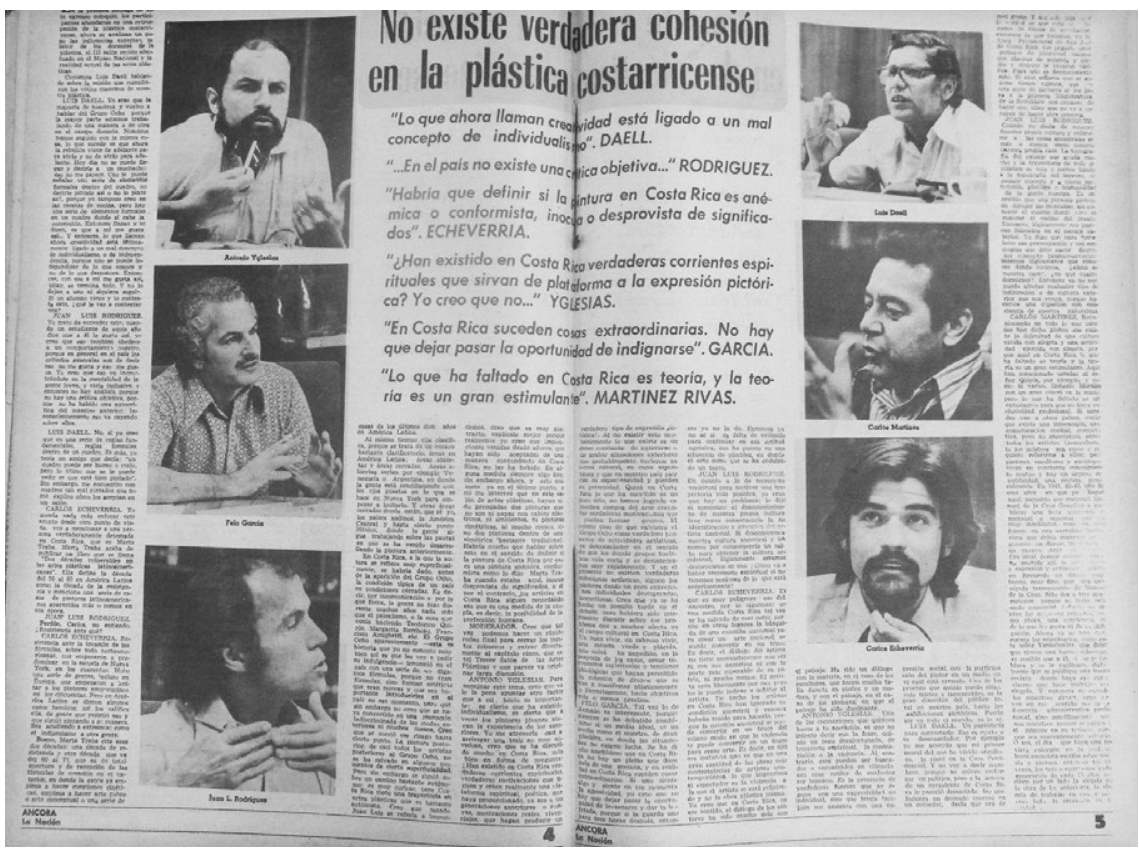

9. "No existe verdadera cohesión en la plástica costarricense", La Nación, Suplemento Ancora, XXIX. I3, 5 de enero de 1975, 4-5. Biblioteca Nacional de Costa Rica.

sobre la historia global, para hacer su trabajo más apetecible ante los ojos de los críticos de arte y el mercado internacional.

En la nota, estos artistas reconocieron que la plácida situación de olvido del pasado histórico costarricense había producido un arte complaciente y poco comunicativo, que hacía referencia a situaciones ajenas al contexto nacional frecuentemente con poca autocrítica; o como lo dijo Traba en 1976, las artes "se han entregado casi voluntariamente a las influencias extranjeras. Han resultado como dicen, cola de león en vez de cabeza de ratón" ${ }^{60}$

A su vez, el artista y arquitecto Felo García agregó que en Costa Rica es famoso por doquier el refrán que reza: "en este país no hay pleito que dure más de una semana" (fig. 9). ${ }^{6}$ Entonces ¿qué podría pretender decir el arte local, si

6o. Cajas Corsi, "Arte actual cola de león en vez de cabeza de ratón", 3.

6I. "No existe verdadera cohesión en la plástica costarricense", 4-5. 
los artistas de Costa Rica olvidaban su pasado, desconocían su identidad, y por ende copiaban adrede o no, fórmulas estéticas y mensajes plásticos ajenos?

Estas inquietudes de los artistas deben ser leídas a la luz del contexto y las características de las políticas culturales promovidas en Costa Rica, por la hegemonía del partido Liberación Nacional en la segunda mitad del siglo xx. Tales políticas se caracterizaron por un interés en legitimar la dominación del partido sobre la vida social y política del país, al crear consenso y dominación. Según Rafael Cuevas Molina, ${ }^{{ }^{6} 2}$ las políticas culturales de este partido político, que gobernó Costa Rica casi ininterrumpidamente en la segunda mitad del siglo XX, muestran la puesta en práctica de una estrategia simbólica en el ejercicio del poder, como detonante de un discurso de cohesión social en la nueva Costa Rica, posterior a la guerra civil de 1948.

De esta manera, el partido gestionó la cultura como medio simbólico para justificar una unidad nacional y un llamado a no disentir. Sin duda, este impulso había calado en el gremio y en general en la cultura nacional. Parte importante de este discurso homogeneizante impuesto por medio de la cultura, echó mano de y revitalizó algunos mitos fundacionales de la nación costarricense, sobre todo con relación a la noción de que Costa Rica era un país pacífico. Estas ficciones de la nación ${ }^{63}$ aparecen a lo largo de la discusión del panel organizado por el periódico La Nación, fundamentalmente cuando se habla del contexto costarricense en "situación de placidez", donde ningún pleito dura más de una semana.

Por otro lado, el hecho de que estos artistas hicieran referencia al tema de la identidad en la plástica costarricense, subraya cómo estos actores le dieron la razón a la crítica realizada por el jurado de la Bienal. De igual modo, estos intercambios en la prensa muestran el interés de algunos miembros del gremio artístico, por problematizar el debate sobre la historia del arte costarricense, de manera tal que se confrontaran sus vacíos y se hiciera una crítica local severa de los motivos que habían estimulado a las artes visuales allí (fig. Io). Más allá de esto, este diálogo de 1975 pone de manifiesto que el desenlace de la Bienal había estimulado un continuo intercambio local sobre las deudas del arte costarricense en la región.

62. Rafael Cuevas Molina, "Estado y cultura en Guatemala y Costa Rica", Anuario de Estudios Centroamericanos I8, núm. 2 (1992): 33.

63. Un artículo fundamental para entender la construcción de la "excepcionalidad" costarricense, véase: Víctor Hugo Acuña Ortega, "La invención de la diferencia costarricense, I8IO-I870", Revista de Historia, núm. 45 (I de enero de 2002): I9I-228. 
DOI: https://doi.org/10.22201/iie.18703062e.2021.119.2763

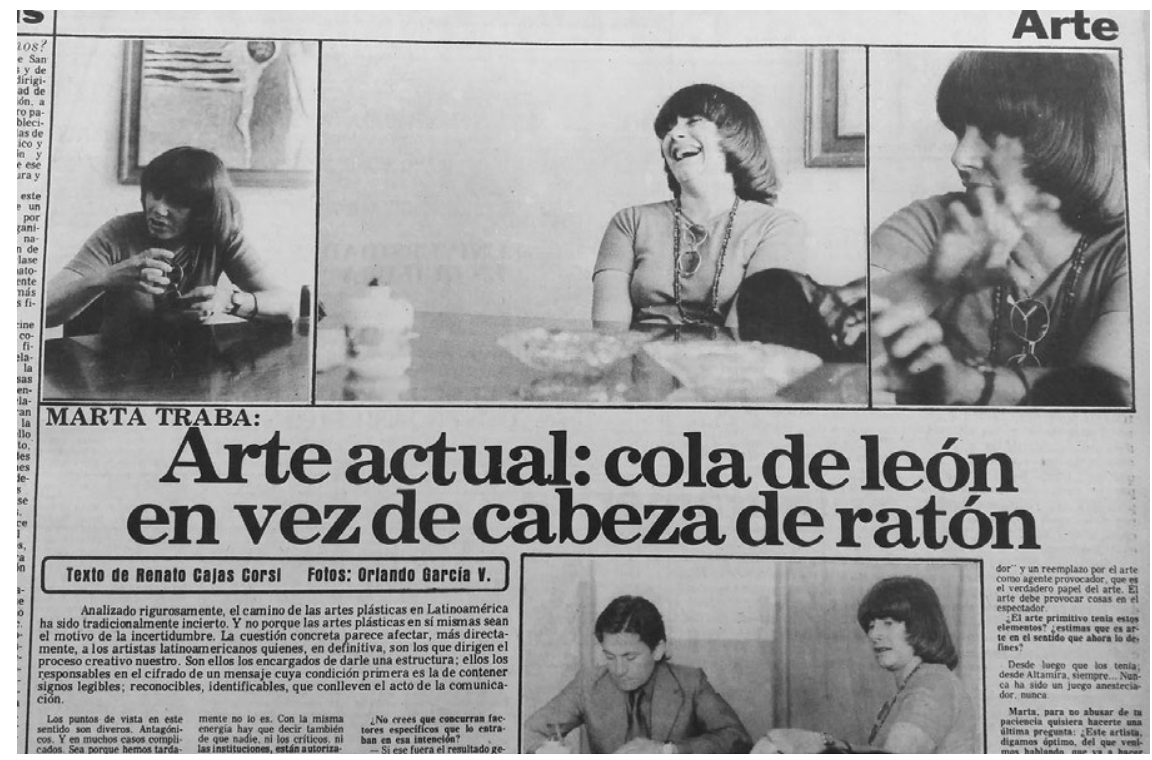

I0. "Arte actual: cola de león en vez de cabeza de ratón", Excélsior 3, 671, I de noviembre de I976, 3 sección 2. Biblioteca Nacional, Costa Rica.

En Guatemala, algunos kilómetros al norte de Costa Rica, la discusión en la prensa fue bastante distinta. En principio, parece que no hubo mayor polémica sobre lo sucedido. En la revisión se encontró un artículo de Manolo Hernández en el que critica la selección de las obras guatemaltecas, por lo que, durante el mes de septiembre, los periódicos publicaron algunas notas explicativas sobre cómo se escogieron las obras concursantes. A pesar de ello, la reacción en la prensa de Guatemala fue completamente celebratoria y exultante de lo sucedido, con justa razón.

En una nota (fig. II) del 30 de septiembre de i97I publicada en el Diario de Centroamérica, se entrevistó a Delia Quiñonez, vocera de relaciones públicas de la Dirección General de Artes Plásticas o bien de la entonces Dirección General de Bellas Artes. En la nota Quiñonez comentó: "Guatemala fue la señora de la Bienal, es decir, se notó la preeminencia de las artes plásticas 


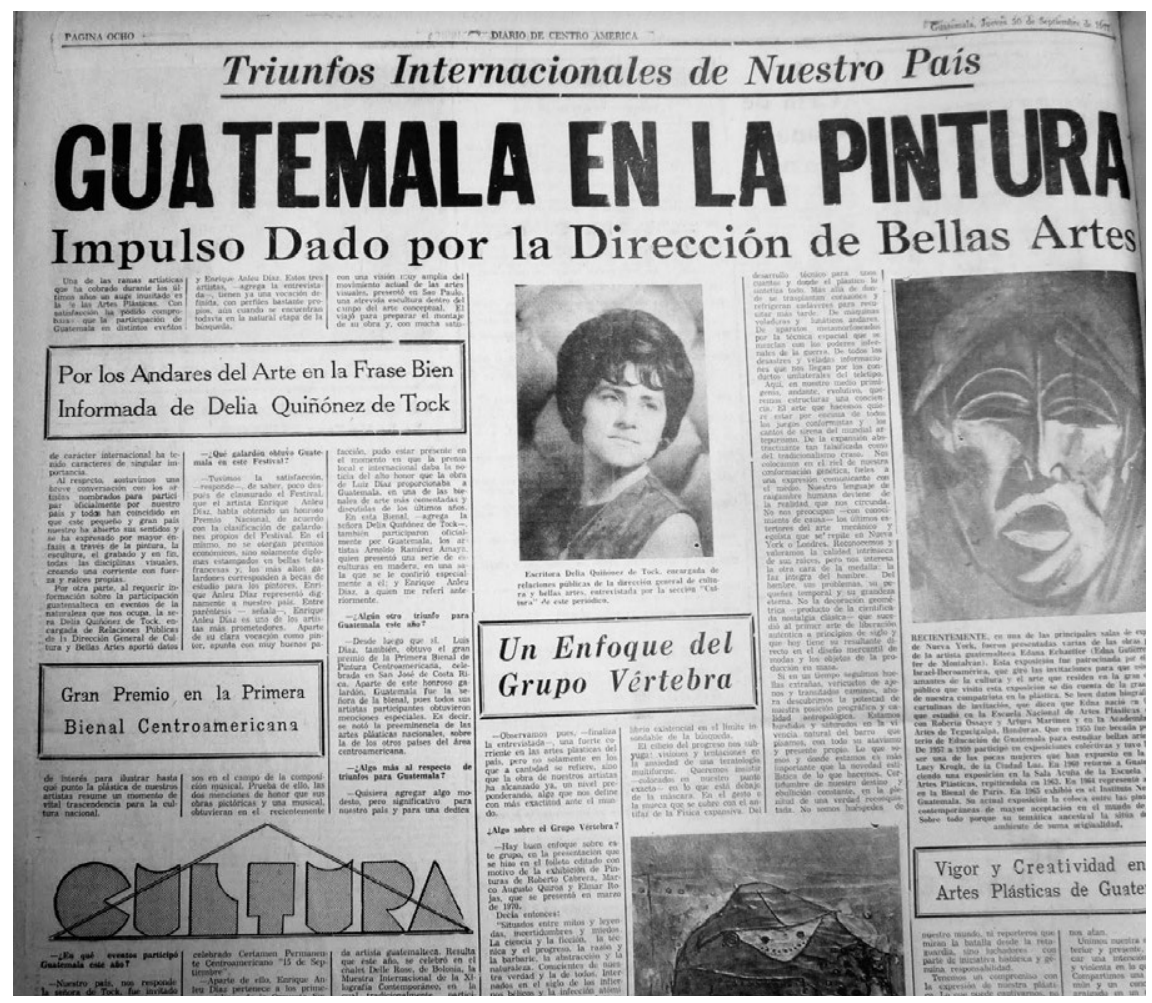

II. "Guatemala en la pintura", Diario de Centroamérica, XCI, 2I208, 30 de septiembre I97I, 8. Fuente: Hemeroteca Nacional, Guatemala.

nacionales por sobre la de otros países del área centroamericana". ${ }^{64}$ Tal fue la tónica de las notas que se consultaron para el caso de Guatemala. Este país, sin titubear, celebró que Luis Díaz "se tragó" la Bienal.

La ausencia de reacciones combativas en la prensa chapina sobre lo sucedido en Costa Rica no es difícil de entender puesto que Luis Díaz había ganado, en cuestión de semanas, tres importantes galardones latinoamericanos: el gran premio en escultura de la XI Bienal de São Paulo, Brasil; el segundo lugar en grabado en el popular Certamen Centroamericano del is de septiembre, orga-

64. "Guatemala en la pintura", Diario de Centroamérica, vol. XCI, núm. 2I208, secc. Nacionales, 30 de septiembre de 1971, 8. 


\section{DOI: https://doi.org/10.22201/iie.18703062e.2021.119.2763}

nizado por la Dirección General de Bellas Artes de 1971, y el gran premio de la Bienal de Pintura de 197I, en Costa Rica.

El triple triunfo de Díaz en estos certámenes representó un orgullo para la instancia local y estatal inmediata que lo había apoyado: la Dirección General de Bellas Artes (DGBA), una de las entidades responsables de organizar al gremio artístico en torno a estas iniciativas y que facilitó el envío de las obras y el tránsito de las y los artistas. La nota del 30 de septiembre en el Diario de Centroamérica muestra el esfuerzo que realizó la DGBA por visibilizar la fortaleza de la institucionalidad oficial del arte en dicho país.

Además de destacar las notas periodísticas en las que se enfatizó la participación de la Dirección General en los triunfos de los artistas guatemaltecos, algunas instancias oficiales como la Universidad de San Carlos, ${ }^{65}$ otorgaron reconocimientos a artistas como Díaz, de manera que se celebraran sus logros en la escena del arte nacional, y se resaltara su papel como embajador de la cultura de Guatemala en el ámbito internacional (fig. I2).

En este sentido, este tipo de actividades demuestran que, al menos para la institucionalidad del arte en Guatemala, hubo una celebración y una reafirmación de la labor internacional que estaban realizando los artistas locales, por su capacidad de ser reconocidos más allá de sus fronteras, tanto en Centroamérica como en el resto de Latinoamérica. Esto queda más claro con el registro en la prensa de otros triunfos de artistas guatemaltecos en la escena internacional a lo largo del periodo, como, por ejemplo, la mención honorífica que recibió la artista Margarita Azurdia por su Serie Asta I04 (de la década de los años sesenta), en la X Bienal de São Paulo de 1969. Lo mismo sucedió a lo largo de los años setenta, con las varias menciones que también recibió Azurdia en el Festival Xerox, y los premios otorgados a otros artistas como Roberto Cabrera, Rodolfo Albularach, entre otros.

En las notas de la prensa chapina, los triunfos de estos artistas en el ámbito internacional fueron vistos como éxitos de las instituciones estatales asociadas al arte. Podríamos intuir también que, de alguna manera, esta cobertura exaltada del arte guatemalteco fue, por un lado, una estrategia para validar el

65. "La Universidad de San Carlos ha decidido felicitar a los artistas que 'tan dignamente representaron a Guatemaila [sic]'”. La rectoría acordó: "Expresar su más calurosa felicitación a quienes obtuvieron los galardones conferidos en el segundo festival cultural centroamericano: el artista Luis Díaz ganador del gran premio centroamericano de pintura, y todos los dramaturgos", en "Id y enseńad a todos", "Felicitan a los artistas laureados", Diario de Centroamérica, vol. XCI, núm. 27202, secc. Sociales, 29 de septiembre de 1971, 7. 


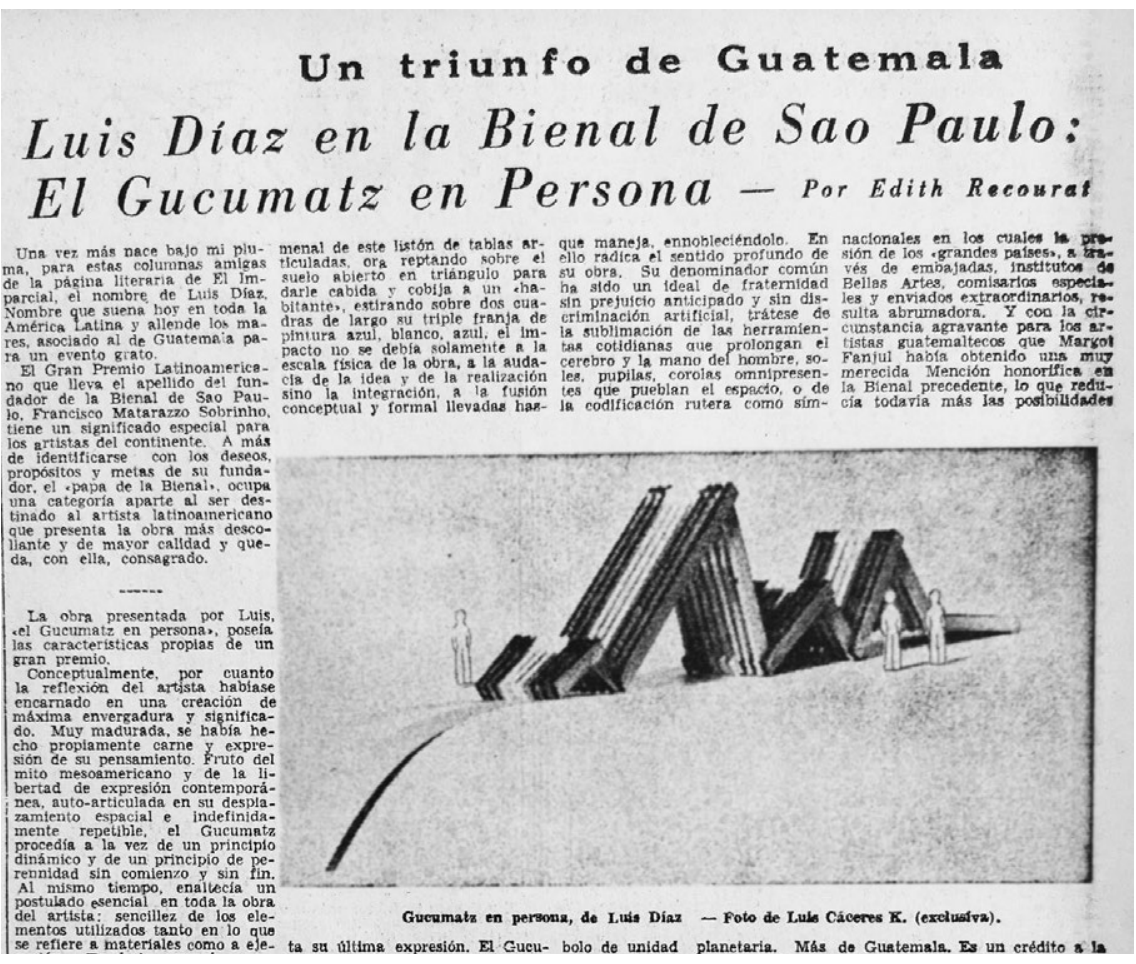

I2. "Un triunfo de guatemala", El Imparcial, L, I6072, II de septiembre de 1971, I3. Fuente: Hemeroteca Nacional, Guatemala.

oficialismo y respaldar el proceder del Estado guatemalteco. Pero, por otro lado, muchos funcionarios de instituciones como la DGBA y algunos artistas fueron verdaderos críticos del Estado, por lo que parece ser que con estos reconocimientos internacionales, el arte les permitió generar un lugar de resistencia y disidencia, por medio del cual reivindicar los aportes de la comunidad artística guatemalteca y defender su contribución cultural internacional.

Esto se daba en una época en que el Estado guatemalteco concentró su poder en el cuerpo militar, como resultado de la pérdida del monopolio de la violencia estatal que se había dado paulatinamente en Guatemala, ante la irrupción de nuevos grupos de seguridad civiles y escuadrones de la muerte, los cuales entraron en pugna unos contra los otros, y que aterrorizaron a la sociedad por décadas. Esta situación, además, se dio en una serie de correlaciones 


\section{DOI: https://doi.org/10.22201/iie.18703062e.2021.119.2763}

de poder en el marco de la Guerra Fría, durante la cual las campañas para controlar a la población y neutralizar a los grupos subversivos en la sociedad chapina aumentó la injerencia militar estadounidense en la región, para asegurar la formación táctica de grupos de choque militares en los países de Centroamérica. En este contexto, sin duda, el arte fue un espacio más en el cual se negociaron diversos intereses geopolíticos en la región.

A la celebración de los artistas, se suman algunas imprecisiones que aparecieron en la prensa de Guatemala. Un ejemplo de ello está en la edición del I9 de septiembre de 1971, del periódico El Gráfico, donde se lee ${ }^{66}$ que, si bien Díaz había ganado el gran premio de 3000 dólares en la Bienal de Costa Rica, se le había dado una mención a todos los artistas guatemaltecos que participaron en el concurso. Además, se afirmó que los demás países de la región ganaron Iooo dólares, cada uno, del premio nacional. Estos dos últimos datos son falsos: los artistas guatemaltecos no recibieron mención honorífica alguna, si bien en el acta del jurado se destacó el trabajo de Elmar Rojas y Roberto Cabrera, y se felicitó en general a la delegación chapina.

Información como ésta se repite en otros periódicos como El Impacto, ${ }^{67}$ que reprodujo sus propias impresiones del acontecimiento, con algunos errores en el reportaje, como señalar que la obra ganadora de la Bienal se titulaba Guatemala y no Guatebala. Al igual que El Gráfico, El Impacto y El Imparcial ${ }^{68}$ reportaron la entrega de mención de honor a todos los artistas guatemaltecos. Este tipo de inconsistencias o errores en la prensa puede atribuirse a la exaltada celebración de los triunfos en los medios guatemaltecos.

El interés en la prensa guatemalteca sobre el tema de la Bienal se hizo presente durante 1971. A diferencia de lo ocurrido en Costa Rica, donde al parecer no se vuelve a mencionar el tema a lo largo de la década de los ańos setenta. Esto también se entiende a la luz de la situación de crisis sociopolítica que vivió Guatemala en esa época, en la que la violencia y el exterminio de grandes contingentes de la población asolaban a la sociedad chapina. Además, en 1976 el país experimentó un catastrófico sismo, que acrecentó las problemáticas sociales que ya existían desde décadas antes, en especial desde 1954, tras el golpe de Estado patrocinado por la CiA, al entonces presidente Jacobo Arbenz.

66. "Luis Díaz gana gran premio C. A en la Bienal de Costa Rica”, El Gráfico, vol. IX, núm. 2606, secc. Nacionales, I9 de septiembre de I97I, 28.

67. s/t, El Impacto, vol. I, núm. 3605, secc. Nacionales, I8 de septiembre de 1971, 5.

68. "Luis Díaz vencedor en Bienal”, El Imparcial, vol. L, núm. I6075, secc. Sociales, I7 de septiembre de 1971, portada-7. 


\section{DOI: https://doi.org/10.22201/iie.18703062e.2021.119.2763}

LA I BIENAL CENTROAMERICANA DE PINTURA

La Bienal, a duras penas logró ocupar un espacio en la prensa de una sociedad que vivió hasta entrada la década de los años noventa el terror de la guerra interna.

\section{Reflexiones finales}

En la segunda mitad del siglo xx tanto en Centroamérica como en Latinoamérica, los certámenes y bienales fueron espacios de experimentación para los artistas de la región. Fueron puentes y vías de intercambio de las artes regionales con un internacionalismo artístico, en especial con relación a los mercados de arte global. Estos espacios, a su vez, permitieron la circulación de otros actores importantes en el ecosistema cultural regional: los críticos de arte e intelectuales vinculados con el arte latinoamericano.

En la década de los años setenta, el debate sobre la existencia y las características del arte latinoamericano se encontraba en su cúspide, por lo que la Bienal evidencia la insatisfacción y la complejidad de las negociaciones en torno a la modernidad artística de la región. Así, la conocida Primera Bienal Centroamericana de Pintura de i97i fue un lugar en el que se cotejó la calidad del arte centroamericano con las corrientes estéticas de la modernidad del arte latinoamericano. Para medir su relevancia, se invitó a un jurado internacional de alto calibre. Esto demuestra también el potencial que tuvieron estos eventos para generar redes culturales entre artistas y otros actores de la escena artística de la región.

Esta Bienal evidencia algunas repercusiones locales tras las tensiones existentes, en torno a la construcción de lo que debía ser el "arte latinoamericano" y dentro de éste, el arte centroamericano. Como en la premiación de la Bienal se desdeñó una serie de obras cercanas a la abstracción o a la figuración abstractizante al menos en el caso de Costa Rica, algunos investigadores han interpretado el fallo del jurado como el causante del impulso que tuvo la neofiguración en el medio costarricense de aquella época. Sin embargo, más allá de las implicaciones estéticas del debate, no se ha realizado una lectura sobre el contexto de esta controversia y lo que ésta nos dice sobre cómo los artistas locales entendieron el lugar del arte moderno centroamericano en el contexto internacional.

El jurado de la Bienal criticó fuertemente el desempeño del arte centroamericano, lo cual generó una crisis local al menos para el caso costarricense. Parece ser que lo que ofendió y confundió a los ticos fue que la Bienal sacó a 


\section{DOI: https://doi.org/10.22201/iie.18703062e.2021.119.2763}

la luz un problema profundo del arte nacional. El arte costarricense no era lo suficientemente internacional, pero tampoco lo suficientemente local para ser capaz de reflejar las particularidades de la experiencia local en la sociedad regional, y así poder competir desde los estándares del arte latinoamericano.

Traba exigió del arte latinoamericano la capacidad de plantear una lectura crítica de la globalidad: una lectura en la que el artista debía entender lo local de su producción, digerir su contexto, pero también insertarse en las implicaciones internacionales de su trabajo (o sea, debía manejar lenguajes globales y estar interconectado con el debate conceptual internacional), para producir un trabajo artístico que dijera algo sobre su contexto, que tuviera un mensaje claro y accesible, y que en términos estéticos resistiera las tendencias aplastantes de los lenguajes plásticos venidos desde los contextos globales del arte, implantados también por los mercados del arte.

El señalamiento del jurado, bastante claro desde la postura de Traba, era que el arte costarricense no tenía intencionalidad. Ante esta crítica algunos actores de la escena local tomaron la oportunidad de reflexionar sobre el peso de la cultura de masas y el imperialismo cultural en el arte local, lo que había generado una reproducción acrítica de tendencias estéticas extranjeras. A su vez, la controversia subrayó la dificultad que tenía el medio costarricense para producir un arte propio y autóctono, ante su desconocimiento de su propia historia y memoria. La teoría de Traba, entonces, había calado en el circuito del arte costarricense.

De igual manera, la Bienal del 7I demuestra la complejidad del debate que se dio en los ańos setenta en torno a lo que era considerado como "arte latinoamericano". En este sentido, autores como Andrea Giunta han explicado que este concepto se había tornado en un "brebaje diabólico", ${ }^{69} \mathrm{o}$ fórmula que nadie podía resolver. No había un consenso sobre lo que debía ser el arte desde acá, por lo que se comenzaron a potenciar artistas individuales, "ya no [...] un conjunto indiferenciado, un magma de artistas unidos por una geografía o una problemática común". $7^{\circ}$

Como se señaló, particularmente en la nota de 1975 , los costarricenses no tenían en claro qué podían aportar como país a ese "brebaje diabólico", que

69. Andrea Giunta, "Crítica de arte y Guerra Fría en la América Latina de la revolución”. Conferencia presentada en La teoría y la crítica de arte en América Latina, Buenos Aires, del 8 al 2I de octubre de 1999, http://www.esteticas.unam.mx/edartedal/PDF/Buenosaires/complets/ giunta_buenosaries99.pdf (consultado el I3 de septiembre 2019).

70. Giunta, "Crítica de arte y Guerra Fría”, I7. 
era entonces el arte latinoamericano. Por su parte, los guatemaltecos parecían más bien considerar que las prácticas artísticas de su país, habían logrado ser exitosamente internacionales sin perder su particularidad local. Es decir, Guatemala había encontrado una manera de generar un pensamiento plástico compatible e inteligible fuera de la región, y por esa razón estaba siendo reconocido internacionalmente.

Asimismo, la Bienal expone el deseo que tenían las y los artistas centroamericanos de insertarse en los circuitos del arte latinoamericano con una voz propia y contundente. A pesar de sus esfuerzos, a grandes rasgos, su trabajo había resultado en general en una "cola de león en vez de cabeza de ratón", en palabras de Traba (fig. Io). Con esta frase, la crítica colombiano-argentina quiso decir que el arte de los países participantes de la Bienal insistía en copiar acríticamente una estética hegemónica que anulaba su propia identidad. El mensaje resultante de este tipo de prácticas fue un producto artificial, indulgente y hasta patético en palabras de Traba. Sobre esto Virginia Pérez-Ratton afirmó que,

a partir de ese evento, y durante varios ańos, la crisis (o mala conciencia) del arte costarricense por no pertenecer a una "identidad centroamericana", provocó que los artistas produjeran algunas obras de pretendido corte político, para poder legitimarse ante la palestra artística latinoamericana, el producto lastimosamente fueron propuestas que "aparecían como impostura de poca relevancia en el contexto local, que pasaba por ańos de progreso económico, industrial e incluso cultural. ${ }^{71}$

Sin embargo, este hecho no sólo impactó al círculo de artistas costarricenses, sino que también implicó una crítica institucional para el anfitrión del concurso: Costa Rica. Ya desde 1971, una editorial en un periódico costarricense postuló la necesidad de que el veredicto del jurado tuviera implicaciones materiales en el país, por lo que el fallo "debe significar para todos los pintores costarricenses un desafío, y sobre todo un despertar pleno, en el sentido de que hay que trabajar con mayor tesón y autenticidad, sobre todo autenticidad y con una labor crítica menos indulgente" ${ }^{72}$ A raíz de la Bienal se organizaron

7I. Pérez-Ratton, “¿Qué región? Apuntando hacia un estrecho dudoso”, 50.

72. "El fallo de la Primera Bienal”, La Nación, vol. XXIV, núm, 8I60, secc. Editorial, i7 de septiembre de I97I, I4. 
charlas, debates y actividades, lo que puso de manifiesto el intenso intercambio sobre la búsqueda de una identidad plástica del gremio local, consciente de que estaba inserto en una cultura del olvido.

Se vio la necesidad de profesionalizar la cultura en el país, con la creación de una institución regidora del arte como lo llegó a ser el Museo de Arte Costarricense. Por ello, artistas como Roberto Cabrera ${ }^{73}$ e investigadoras como Gabriela Sáenz Shelby han afirmado que el resultado de la Bienal tuvo un impacto directo en la consolidación de este museo en 1978. Para Sáenz, "el hecho contundente de la deslegitimación del arte costarricense ante sus vecinos y al interno, evidenció la necesidad de establecer políticas culturales más asertivas desde el Estado para apoyar y promover la producción artística y de la plástica nacional". ${ }^{74}$

En términos metodológicos y teóricos, el caso de la Bienal es un importante ejercicio analítico que devela el gran potencial que se puede obtener de investigaciones comparadas sobre el arte centroamericano, las cuales evidencian las transferencias e influencias culturales entre nuestros países. No queda duda que hay muchas otras polémicas que es necesario revivir y conocer aún sobre nuestra historia compartida. En definitiva, sobre la Bienal de 197I es evidente que "parte del gran valor que significó Marta Traba para la crítica regional no radica en la infalibilidad de sus fallos, sino en las polémicas que fue capaz de suscitar". ${ }^{75}$ is

73. Roberto Cabrera, Veinte años de la pintura costarricense, 1970-199o (San José, Costa Rica: Banco de San José, 1990), I2.

74. Gabriela Sáenz Shelby, "Historia de las políticas de coleccionismo y de representación de las artes visuales en Costa Rica (1950-2006). Estudio comparativo de tres instituciones públicas: BCCR, MAC Y MADC", tesis de maestría en Historia (San José: Universidad de Costa Rica, 2013), 65.

75. Steinmetz, "Antecedentes a la posición de Marta Traba", 67. 